\title{
Improved rhizoremediation for decabromodiphenyl ether (BDE-209) in E-waste contaminated soils
}

\author{
Jiayin Feng ${ }^{1,2}$, Xinquan Shen ${ }^{1,2}$, Jian $\mathrm{Chen}^{3}$, Jiachun Shi ${ }^{1,2}$, Jianming $\mathrm{Xu}^{1,2}$, Caixian Tang ${ }^{1,4}$, \\ Philip C. Brookes ${ }^{1,2}$, Yan He ${ }^{1,2, *}$
}

1 Institute of Soil and Water Resources and Environmental Science, College of Environmental and Resource Sciences, Zhejiang University, Hangzhou 310058, China

2 Zhejiang Provincial Key Laboratory of Agricultural Resources and Environment, Hangzhou 310058, China

3 Farmland Quality and Fertilizer Management Station of Wenling, Zhejiang Province, Wenling 317500, China

4 Department of Animal, Plant and Soil Sciences, La Trobe University, Bundoora, Victoria 3086, Australia

\section{ARTICLE I NFO}

Article history:

Received June 19, 2018

Revised October 17, 2018

Accepted October 23, 2018

\section{Keywords:}

Decabromodiphenyl ether (BDE-209)

Rhizoremediation

Ryegrass

Rice

Compost

Arbuscular mycorrhizal fungi

\section{A B S T R A C T}

An experiment was conducted to improve rhizoremediation for decabromodiphenyl ether (BDE-209) contaminated soil from typical E-waste dismantling areas. Plants of ryegrass (Lolium perenne L.) and rice (Oryza sativa L.) were cultivated in aged-contaminated (initial concentration of $346.3 \mu \mathrm{g} \mathrm{BDE}-209 \cdot \mathrm{kg}^{-1}$ ) and freshly-spiked (initial concentration of $3127 \mu \mathrm{g}$ $\mathrm{BDE}-209 \cdot \mathrm{kg}^{-1}$ ) soils, coupling with the agricultural modification strategies of compost addition and/or arbuscular mycorrhizal fungi (AMF) infection, respectively. 60 days' growth of ryegrass significantly facilitated the dissipation of BDE-209, with the most effective in its rhizosphere in treatment inoculated with AMF; the BDE-209 dissipation rates achieved $51.9 \%$ and $22.8 \%$ in rhizosphere, and $43.5 \%$ and $19.8 \%$ in non-rhizosphere, for aged-contaminated and freshlyspiked soils, respectively. 120 days' growth of rice with simultaneous inoculation of AMF and addition of compost was the most effective in facilitating BDE-209 dissipation in agedcontaminated soil, with the removal rates of $53.3 \%$ and $48.1 \%$ in rhizosphere and nonrhizosphere soils respectively; while for freshly-spiked soils, the most effective removal was achieved by compost addition only, with the BDE-209 dissipation rates of $27.9 \%$ and $26.6 \%$ in rhizosphere and non-rhizosphere soils, respectively. High throughput sequencing analysis of rhizosphere soil DNA showed that responses in microbial communities and their structure differed with plant species, soil pollution dose, AMF inoculation and/or compost addition. Actinomycetales, Xanthomonadales, Burkholderiales, Sphingomonadales, Clostridiales, Cytophagales, Gemmatimonadales and Saprospirales were the sensitive responders and even possibly potential functional microbial groups during the facilitated removal of BDE-209 in soils. This study illustrates an effective rhizoremediation pattern for removal of BDE-209 in pollution soils, through successive cultivation of rice and followed by ryegrass, with rice growth coupled with AMF inoculation and compost addition, while ryegrass growth coupled with AMF inoculation only.

(c) Higher Education Press 2019

\footnotetext{
* Corresponding author

E-mail address: yhe2006@zju.edu.cn (Y. He)
} 


\section{Introduction}

With the development of world economy, the growing electronic waste has caused serious environmental problems on the global scale, especially in China. In typical E-waste dismantling area, polybrominated diphenyl ethers (PBDEs), used as flame retardants in electronic components, have drawn great public attention. Their environmental release during non-standard dismantling of E-waste has caused serious contamination in Taizhou and Guiyu of China, two of the largest E-waste dismantling sites in the world ( $\mathrm{He}$ et al., 2015). Previous pollution surveys reported that the total concentration of PBDEs reached to greater than $3000 \mu \mathrm{g} \cdot \mathrm{kg}^{-1}$ which caused serious environmental damage and food security risk (Qu et al., 2007; Zhao et al., 2010; Wang et al., 2011b). Especially, the reported concentration of PBDEs ranged from 4.8 to $533 \mu \mathrm{g} \cdot \mathrm{kg}^{-1}$ and $2.1-217 \mu \mathrm{g} \cdot \mathrm{kg}^{-1}$ in soil and vegetation respectively in Guiyu (Wang et al., 2011b) and from 2.96 to $200 \mu \mathrm{g} \cdot \mathrm{kg}^{-1}$ (with a mean of $65.2 \mu \mathrm{g} \cdot \mathrm{kg}^{-1}$ ) for farmland soils in Taizhou (Dong et al., 2014). Therefore, facilitating environmental removal of PBDEs from polluted soils is crucial for pollution control and remediation in these Ewaste dismantling areas (Deng et al., 2016). Of all the 209 kinds PBDE congeners, the highest brominated decabromodiphenyl ether (BDE-209) owns the highest amount in total production of PBDEs because of its lower price and superior performance (Sjödin et al., 1999; He et al., 2015). There is thus an urgent need to mitigate the heavy pollution of BDE209.

Currently, available methods for facilitating the dissipation of PBDEs in soil basically rely on either abiotic or biotic pathways. The photolytic debromination, Fenton and nanoscale zero valent iron methods are common and important abiotic techniques (Oturan et al., 2000; Ahn et al., 2006; Qiu et al., 2011; Wei et al., 2013). Although they are highly efficient for remediation, these techniques are usually not the best for farmland soils, due to their high costs, secondary pollution and drawbacks for agricultural production. Therefore, green biotic remediation techniques such as bioremediation through the growth of plants are more and more favorable (Huang et al., 2013; He et al., 2015). Benefits of plant growth were verified in facilitating the dissipation of organic contaminants (OCs) in plant rhizosphere (e.g. He et al., 2005, 2007, 2009), with the effects regulated by root exudates, root architecture, rhizosphere microbial communities, soil water and nutrient conditions, pollutant stress and aging effect simultaneously (Ma et al., 2010). Especially, the enhanced microbial degradation either aerobically or anaerobically initiated by rhizosphere effect was reported to be the key process underpinning the facilitated removal of OCs from polluted soils (Zhu et al., 2014; Chen et al., 2015). The beneficial effect is also plant-specific, due to the contrasting root secretion, particularly in different aerobic and anaerobic conditions. So far, various plant species have been tested for the potential functional species with high efficiency in pollution remediation of typical OCs, such as PBDEs, polychlorinated biphenyls (PCBs), polycyclic aromatic hydrocarbons (PAHs) and pentachlorophenol (PCP), including the xerophyte species such as maize, ryegrass, tall fescue, lettuce and the hygrocolous species such as rice, zucchini (Huang et al., 2010; Wang et al., 2011a; Inui et al., 2011; Kuo et al., 2014; Wang et al., 2014; Qin et al., 2014; He et al., 2015; Zhang et al., 2015; Bizkarguenaga et al., 2016). As for PBDEs, the ryegrass (Lolium perenne L.) and the rice (Oryza sativa L.) cultivars (Xiushui 134) were recommended as the most functional plant species for a cost-effective remediation of soils polluted by BDE-209 around an e-waste recycling area by a screening experiment coupling with regulation of soil redox status during plant growth ( $\mathrm{He}$ et al., 2015).

The agronomic practices, such as compost addition and mycorrhizal fungi inoculation, are previously studied and verified to be helpful for OCs dissipation through their modification in physical and biochemical properties of polluted soils, thereby improved pollution remediation (Cheng and Wong, 2008; Wang et al., 2011a; Wu et al., 2014; He et al., 2015; Bizkarguenaga et al., 2016;). Apart from the positive effect on soil microbial activity, the addition of compost, known as the most economical and widespread method around the world, was shown to accelerate soil dissipation of PBDEs and PAHs previously (Kästner et al., 1995; Cheng and Wong, 2008; Bizkarguenaga et al., 2016). Arbuscular mycorrhizal fungi (AMF) colonization in ryegrass rhizosphere was also reported capable of mediating the microbial growth and community structure quantitatively and qualitatively, and thus enhanced the dissipation of BDE-209 (Wang et al., 2011a). Analyses on the response of functional microbial groups during facilitated soil dissipation of BDE-209 also revealed an increase in biomass of AMF (He et al., 2015).

The objectives of this study were to develop an efficient rhizoremediation approach to enhance the removal of BDE209 in e-waste recycling areas. Plant-microbe synergistic pot experiments were conducted to elucidate the combined rhizospheric and microbiological effect on BDE-209 removal. This study included two plant species (ryegrass and rice), various pollution dose and time (aged and freshly-spiked), along with agronomic practices (AMF inoculation in the form of Glomus mosseae, and/or compost addition). It was hypothesized that the inoculation of AMF and/or addition of compost would alter plant-microbe interactions during plant growth and thereby affect BDE-209 removal, with the effect differing between rhizosphere and non-rhizosphere where the microhabitats were regulated by specific plant growth as well as soil pollution and nutrition conditions.

\section{Materials and methods}

\subsection{Chemicals}

BDE-209 was Acros standard with the purity of 99\% (Acros Organics, Belgium). All solvents used, i.e. acetone, $n$-hexane, toluene, and methanol, were HPLC grade and obtained from Sonice Biotech Company (Hangzhou, China). 


\subsection{Soil collection and preparation}

Surface soils $(0-20 \mathrm{~cm})$ were collected from a farmland at Mukeng, the most seriously polluted village in Taizhou district of China $\left(28^{\circ} 21^{\prime} 48.58 " \mathrm{~N}, 121^{\circ} 15^{\prime} 44.11^{\prime \prime} \mathrm{E}\right)$. Selected characteristics of the soil were as follows: $\mathrm{pH}$ (soil:water $=1: 2.5$ ) 6.57 ; organic matter, $35.6 \mathrm{~g} \cdot \mathrm{kg}^{-1}$; cation exchange capacity, $9.24 \mathrm{cmol} \cdot \mathrm{kg}^{-1}$; available $\mathrm{P}\left(\mathrm{NH}_{4} \mathrm{~F}-\mathrm{HCl}\right.$ extraction $), 65.3$ $\mathrm{mg} \cdot \mathrm{kg}^{-1}$; available $\mathrm{K}\left(\mathrm{NH}_{4} \mathrm{OAc}\right.$ extraction), $333.9 \mathrm{mg} \cdot \mathrm{kg}^{-1}$; clay $14.4 \%$, silt $22.2 \%$, and sand $63.4 \%$. Soil samples were air-dried and sieved $<2 \mathrm{~mm}$ before use. The initial concentration of BDE-209 in this soil was $346.3 \mu \mathrm{g} \cdot \mathrm{kg}^{-1}$.

Two pollution groups of BDE-209 with different pollution dose and aged time were designed. One was the agedcontaminated soils with low pollution that were collected directly from the field, and the other was freshly-spiked soils with high pollution that were amended with additional BDE209, giving an average BDE-209 concentration of 3127 $\mu \mathrm{g} \cdot \mathrm{kg}^{-1}$. Freshly-spiked contaminated soil was prepared as follows: $1 \mathrm{~kg}$ soil was spiked with a solution of BDE-209 that was dissolved in $100 \mathrm{~mL}$ of a mixture of toluene and acetone ( $V: V=1: 10)$, mixed thoroughly, and placed under a fume hood for solvent evaporation for $24 \mathrm{~h}$. The spiked soil was continuously tumbled with $9 \mathrm{~kg}$ non-spiked soil for $2 \mathrm{~h}$, then continuously tumbled with other non-spiked soil to ensure efficient mixing. Soil samples of both pollution groups were amended with basal nutrients at rates of $300 \mathrm{mg} \mathrm{N}$ (urea), 100 $\mathrm{mg} \mathrm{P}$ (ground phosphate rock), and $200 \mathrm{mg} \mathrm{K} \cdot \mathrm{kg}^{-1}$ (muriate of potash) before sowing seeds.

\subsection{Pot experiment design}

The ryegrass (Lolium perenne L.) and rice (Oryza sativa L. "Xiushui 134") were selected as the test plants. The two species have been verified as the most efficient species for BED-209 phytoremediation in our previous study (He et al., 2015). Seeds were sterilized in $10 \%(\mathrm{v} / \mathrm{v}) \mathrm{H}_{2} \mathrm{O}_{2}$ solution for 15 min, followed by washing with deionised water twice, soaked in a $3 \mathrm{mM}$ solution of $\mathrm{Ca}\left(\mathrm{NO}_{3}\right)_{2}$ for $4 \mathrm{~h}$ in the dark. The seeds were subsequently germinated for a week on moist filter paper in the dark

A rhizobag pot experiment was conducted following a modification of the method of He et al. (2015). The dimension of the rhizobag was $200 \times 100 \times 180$ (length $\times$ width $\times$ height in $\mathrm{mm}$ ), which was made by nylon mesh $(<25 \mu \mathrm{m})$. Soils were used to fill the inside (as rhizosphere) and enclosed the outside (as non-rhizosphere) of the rhizobag. Each pot received $4 \mathrm{~kg}$ of polluted soil, with BDE-209-free soil covered on the upper $0.5 \mathrm{~cm}$ as a buffer layer to minimize the loss of BDE-209 due to volatilization and photolysis. Uniform seedlings ( 3 for rice and 25 for ryegrass per pot) were selected and transplanted into the root bag. Plants of ryegrass and rice were grown in a greenhouse for 60 and 120 days, respectively. At harvest, rhizosphere and non-rhizosphere soils were sampled separately. Ryegrass and rice plants were also sampled to separate shoots and roots.

The treatments were set up as follows: 1) control without plant (CK); 2) plants inoculated with AMF Glomus mosseae (G. mosseae) (+ G. mosseae); 3) plants amended with compost (+compost); 4) plant growth with $G$. mosseae inoculation and compost addition ( + G. mosseae + compost). Original inoculum of the AMF G. mosseae (BGC GZ01A) (Institute of Plant Nutrition and Fertilizers, Beijing Academy of Agronomy and Forestry, China) was comprised of a sandy soil containing spores, mycelium and sorghum root fragments, and was air-dried and sieved $(<2 \mathrm{~mm}$ ) before use. Mycorrhizal treatments were prepared by mixing the fungal inoculum with soil at about $1: 9$ ratio $(\mathrm{W}: \mathrm{W})$, with the mixtures placed within the rhizobag (Wang et al., 2011a). Compost treatment was prepared with the mixture of $33.2 \mathrm{~g}$ pig manure compost and $3.97 \mathrm{~kg}$ soil per pot. Given that the physiologic needs are plant species-dependent, the soil water status was managed differentially for the growth of ryegrass and rice. Soil moisture content was maintained at approximately $60 \%$ of the field water holding capacity (WHC) for the ryegrass. With respect to the rice, a sequential wetting-drying condition was created, with a 2-cm water layer covering the soil surface to produce flooded state in the initial stages followed by a dry state through flushing out the redundant water and withholding from watering until the moisture contents decreased below $60 \%$ WHC. Therefore, experiment treatments for ryegrass group include: dry control (CK-Ry), Ryegrass growth only (Ry), Ryegrass + G. mosseae (RyG), Ryegrass + compost (RyC) and Ryegrass + G. mosseae + compost (RyGC); and that for rice group include: sequential wetting-drying control (CK-Ri), Rice growth only (Ri), Rice + G. mosseae (RiG), Rice + compost (RiC) and Rice + G. mosseae + compost (RiGC). Each treatment was conducted separately for aged-contaminated and freshly spiked soils, with three replicates. The original aged (O-aged) and freshly-spiked (O-fresh) contaminated soil samples before the experiment commenced were also used for analysis of initial microbial status.

\subsection{Soil chemical analysis}

The concentration of BDE-209 in soils was determined by a method based on ultrasonic extraction, subsequent solid phase enrichment followed by GC- $\mu$ ECD analysis. The detail extraction, clean up as well as detected methods for the detection of BDE-209 from soil and plant samples had been reported in our earlier study (He et al., 2015). Briefly, each $2 \mathrm{~g}$ soil sample was ultrasonically extracted thrice with a mixture of acetone and hexane $(1: 1, \mathrm{v} / \mathrm{v})$ added with a certain amount of anhydrous sodium sulfate and 1-g activated copper granules. The supernatant after centrifugation were combined and concentrated, followed by solid phase micro-extraction with the isooctane and Florisil SPE column $(6 \mathrm{~mL}, 1 \mathrm{~g})$. The resulting eluents were then dried under a stream of $\mathrm{N}_{2}$, and further re-dissolved with $1 \mathrm{~mL}$ hexane and analyzed by GC (Agilent 6890II, USA). Quality assurance protocol included the addition of random injection of solvent blanks and standards. The recoveries of BDE-209 was $93.4 \pm 1.68 \%$.

Soil dissolved organic carbon (DOC) and dissolved total nitrogen (DTN) were extracted with Milli-Q water, and the 
supernatant was measured using an automated total organic carbon analyzer (Multi N/C 3100, Analytik Jena AG, Jena, Germany) (Xu et al., 2015; Dai et al., 2016). The $\mathrm{NH}_{4}{ }^{+}$and $\mathrm{NO}_{3}{ }^{-}$concentrations were measured using a continuous flow analyzer (TRAACS 2000, Bran and Luebbe, Norderstedt, Germany) after soil samples were extracted with $1 \mathrm{~mol} \cdot \mathrm{L}^{-1}$ $\mathrm{KCl}$ (Zhou et al., 2014). The concentration of $\mathrm{Fe}^{2+}$ and $\mathrm{Fe}^{3+}$ was measured using the 1,10-phenanthroline colorimetric method at $530 \mathrm{~nm}$ on a UV-Vis spectrophotometer (Hayat et al., 2011; Xu et al., 2014). The catalase activity was determined by back-titrating residual $\mathrm{H}_{2} \mathrm{O}_{2}$ with $\mathrm{KMnO}_{4}$ as described by Stepniewska et al. (2009) and the dehydrogenase activity was analyzed after incubation soil samples in TTC-glucose-Tris buffer solution at $37^{\circ} \mathrm{C}$ in the dark for $24 \mathrm{~h}$ (Liu et al., 2011). Dry weights of shoots and roots were recorded.

\subsection{Soil DNA extraction and illumina sequencing}

The microbial community of soil samples in rhizosphere
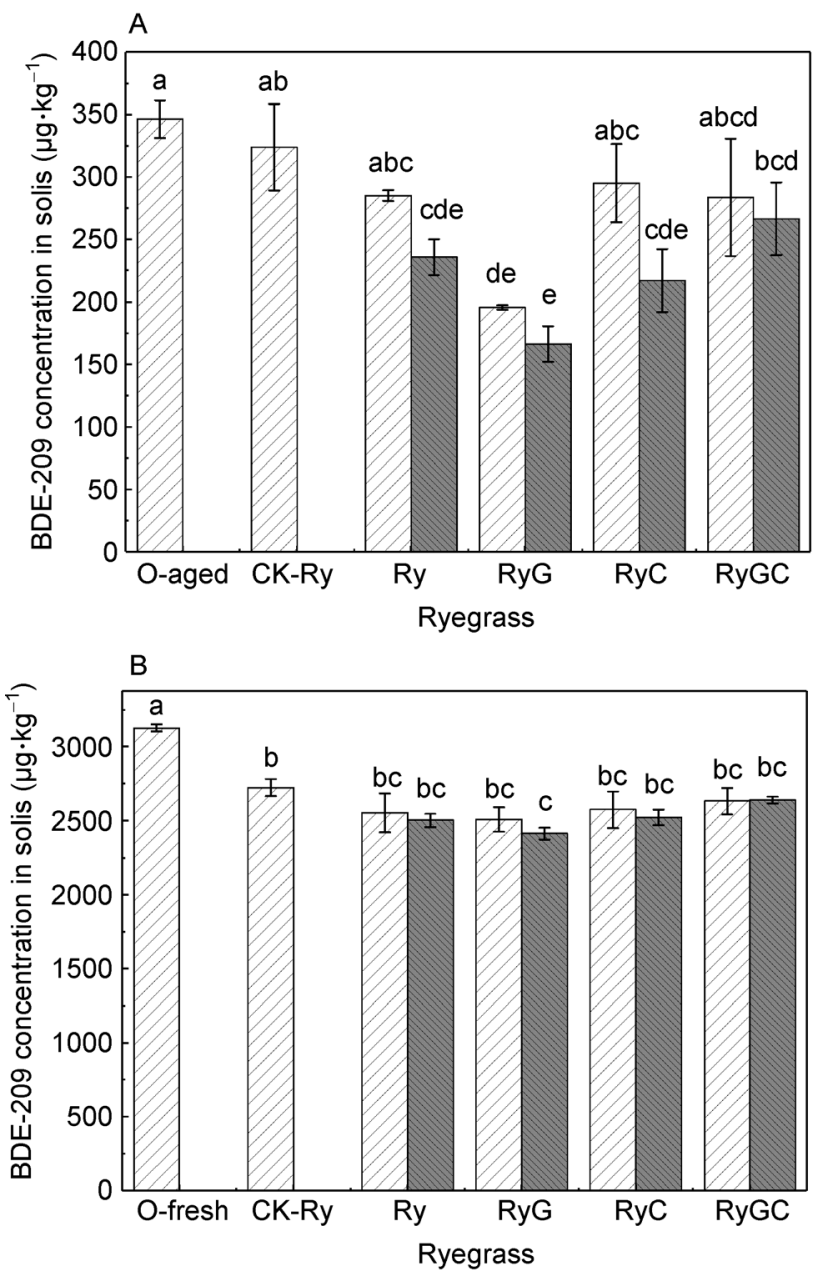

collected at harvest was analyzed through amplification and sequencing of a $16 \mathrm{~S}$ rRNA amplicon using Illumina Miseq high-throughput sequencing. Total microbial genomic DNA was extracted from $0.5 \mathrm{~g}$ of soil sample using the MoBio PowerSoil DNA Isolation Kit (MoBio Laboratories, Carlsbad, CA, United States) according to the manufacturer's instruction. Each DNA extract was amplified by the polymerase chain reaction (PCR) with the primer pair 520F (5-AYTGGGYDTAAAGNG-3) and 802R (5-TACNVGGGTATCTAATCC-3) to obtain an approximately 250-bp fragment on the $V 4$ region of the $16 \mathrm{~S}$ rRNA gene. Genome DNA would be normalized to 30 ng per PCR reaction. V4 dual-index Fusion PCR Prime Cocktail and PCR Master Mix (NEB Phusion High-Fidelity PCR Master Mix) was added to the PCR run. Amplification was conducted using the PCR conditions: $30 \mathrm{~s}$ at $98^{\circ} \mathrm{C}, 25$ cycles of $30 \mathrm{~s}$ at $98^{\circ} \mathrm{C}, 30 \mathrm{~s}$ at $50^{\circ} \mathrm{C}$ and $30 \mathrm{~s}$ at $72^{\circ} \mathrm{C}$, and a final 5 -min extension at $72^{\circ} \mathrm{C}$. PCR products were purified with AmpureXP beads (Agencourt) to remove the unspecific products. The final library was qualified by PicoGreen (Invitrogen, Paisley, UK). Qualified libraries were sequenced
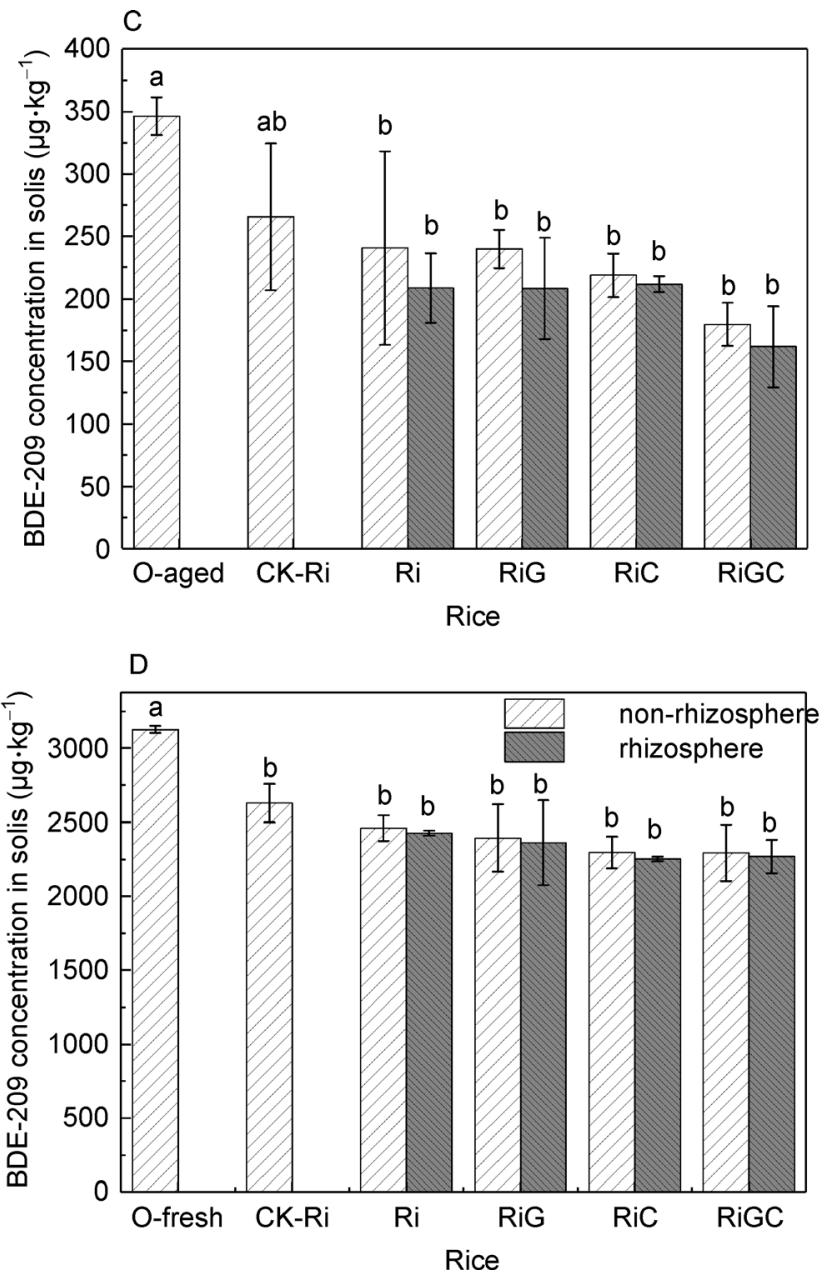

Fig. 1 The concentration of BDE-209 in soils of ryegrass (A and B) and rice (C and D) experiments (A and C: aged-contaminated soil; $B$ and D: freshly-spiked soil). Bars are the standard error of means of three replicates. Different letters indicate significant differences among treatments at the $P<0.05$ level. Abbreviations for treatments: O-aged and O-fresh, original aged and freshly-spiked contaminated soil samples before the experiment commenced, respectively; others are as Table 1. 
Table 1 The removal percentage of BDE-209 in rhizosphere (RS) and non-rhizosphere (NRS) of aged-contaminated and freshly-spiked soils of different treatments.

\begin{tabular}{|c|c|c|c|}
\hline & Treatments & Aged-contaminated soil (\%) & Freshly-spiked soil (\%) \\
\hline CK-Ry & & $6.5 \mathrm{e}$ & $12.9 \mathrm{e}$ \\
\hline \multirow[t]{2}{*}{ Ry } & NRS & $17.7 \mathrm{de}$ & $18.4 \mathrm{bcd}$ \\
\hline & RS & $31.9 c$ & $20.0 \mathrm{ab}$ \\
\hline \multirow[t]{2}{*}{ RyG } & NRS & $43.5 a b$ & $19.8 \mathrm{abc}$ \\
\hline & RS & $51.9 a$ & $22.8 \mathrm{a}$ \\
\hline \multirow[t]{2}{*}{ RyC } & NRS & $14.8 \mathrm{de}$ & $17.7 \mathrm{bcd}$ \\
\hline & RS & $37.3 \mathrm{bc}$ & 19.3abcd \\
\hline \multirow[t]{2}{*}{ RyGC } & NRS & $18.1 d$ & $15.9 \mathrm{cde}$ \\
\hline & RS & $23.0 \mathrm{~cd}$ & 15.6de \\
\hline CK-Ri & & $23.3 c$ & $15.9 b$ \\
\hline \multirow[t]{2}{*}{$\mathrm{Ri}$} & NRS & $30.5 b$ & $21.3 a b$ \\
\hline & RS & $39.7 a b$ & $22.4 a b$ \\
\hline \multirow{2}{*}{ RiG } & NRS & $30.8 b$ & 23.5ab \\
\hline & RS & $39.8 a b$ & $24.5 a$ \\
\hline \multirow[t]{2}{*}{$\mathrm{RiC}$} & NRS & $36.8 a b$ & $26.6 a$ \\
\hline & RS & $38.8 a b$ & $28.0 \mathrm{a}$ \\
\hline \multirow[t]{2}{*}{ RiGC } & NRS & 48.1ab & $26.7 a$ \\
\hline & RS & $53.3 a$ & $27.5 a$ \\
\hline
\end{tabular}

Abbreviations for treatments: CK-Ry, dry control of ryegrass group; Ry, Ryegrass growth only; RyG, Ryegrass + G. mosseae; RyC, Ryegrass + compost; RyGC, Ryegrass + G. mosseae + compost; CK-Ri, sequential wetting-drying control of rice group; Ri, Rice growth only; RiG, Rice + G. mosseae; RiC, Rice + compost; RiGC Rice + G. mosseae + compost; NRS, Non-rhizosphere soil; RS, Rhizosphere soil. Values in the same column with different plant species followed by different letters are significantly different $(P<0.05)$.

pair end on the Illumina MiSeq platform with sequencing strategy PE250 (MiSeq Reagent Kit). Illumina (Highseq2000, Illumina, San Diego, CA, US) sequencing services were provided by the Personal Biotechnology Co., Ltd. (Shanghai, China). The sequences were submitted to the NCBI Sequence Read Archive (SRA) database (with accession number SRP132106).

\subsection{Statistical analysis}

Statistical analysis was conducted using the SPSS 20.0 software package (IBM, Armonk, IL, United States). Means and standard error were calculated for triplicates, with significant differences tested by one-way analysis of variance (ANOVA) with LSD test at $P<0.05$. The redox biochemical criteria in ryegrass and rice experiments were further identified using correlation tests of significant principal component scores of PCA by Origin 8.1. Redundancy analysis (RDA) was performed using the $\mathrm{R}$ version 3.4 .2 and Origin 8.1.

\section{Results}

\subsection{The concentration of BDE-209 in soils}

In general, the BDE-209 dissipation rates (as percentage removal of the initial amounts) in aged-contaminated soils $(14.8 \%-53.3 \%)$ were higher than those in freshly-spiked soils
(15.6\%-28.0\%) (Table 1). In the ryegrass group (Fig. 1A and $1 \mathrm{~B})$, soil BDE-209 concentration in the treatments with plants was significantly lower than the initial value of original soil samples before experiment (O-aged and $\mathrm{O}$-fresh) and that in the control without plants, with the concentration in rhizosphere lower than non-rhizosphere. Ryegrass growth enhanced BDE-209 dissipation in soil, with the most effective in the RyG treatment, in which BDE-209 dissipation rates achieved $51.9 \%$ and $22.8 \%$ in rhizosphere, and $43.5 \%$ and $19.8 \%$ in non-rhizosphere, for aged-contaminated and freshly-spiked soils, respectively (Table 1). In aged-contaminated soils, the dissipation rate of BDE-209 followed the order of RyG>RyC>Ry>RyGC. The same order was also found in freshly-spiked soils, but the differences among the treatments were not significant.

In the rice group (Fig. $1 \mathrm{C}$ and $1 \mathrm{D}$ ), the growth of rice can effectively decrease soil BDE-209 relative to the original samples and the CK, and BDE-209 concentration in rhizosphere were lower than that in non-rhizosphere as well. In aged-contaminated soils, the RiGC treatment was the most effective in facilitating BDE-209 dissipation, with the dissipation rates of $53.3 \%$ and $48.1 \%$ in rhizosphere and nonrhizosphere, respectively. The dissipation rate followed the order of RiGC>RiG>Ri>RiC. While in freshly-spiked soils, the most effective treatment was in the treatment of $\mathrm{RiC}$, with the BDE-209 dissipation rates of $28.0 \%$ and $26.6 \%$ in rhizosphere and non-rhizosphere, respectively (Table 1). The general dissipation trend was RiC>RiGC>RiG>Ri. However, no 
significant differences among treatments were found either in aged-contaminated or freshly-spiked soils.

\subsection{The concentration of BDE-209 in plants}

The shoot biomass of ryegrass and rice were both highest in RyGC/RiGC and RyC/RiC of aged-contaminated and freshlyspiked treatments, respectively. While for root issue, RyG had the highest biomass in aged-contaminated treatment, but lowest biomass in freshly-spiked soils. What's more, the root biomass of rice was significantly higher in $\mathrm{RiC}$ than that in other treatments, which was similar to shoot biomass of rice $(P<0.05)$ (Table 2).

With respect to the concentrations of BDE-209 in ryegrass and rice, BDE-209 residues in ryegrass were only detected in the roots of RyG $\left(154.6 \mu \mathrm{g} \cdot \mathrm{kg}^{-1}\right)$ and RyC $\left(96.2 \mu \mathrm{g} \cdot \mathrm{kg}^{-1}\right)$ treatments in aged-contaminated soils; and accumulation of BDE-209 was detected in roots of all treatments (419.8-495.9 $\left.\mu \mathrm{g} \cdot \mathrm{kg}^{-1}\right)$ and in shoots of RyGC treatment $\left(16.4 \mu \mathrm{g} \cdot \mathrm{kg}^{-1}\right)$ in freshly-spiked soils. Comparatively, BDE-209 residue was detected in neither the roots nor the shoots of rice in agedcontaminated soils; there was also no BDE-209 accumulation in shoots, but the roots were detected with BDE-209 in all treatments $\left(60.8-85.5 \mu \mathrm{g} \cdot \mathrm{kg}^{-1}\right)$ in freshly-spiked soils (Table 2).

\subsection{Changes of soil biochemical indexes}

The concentrations of DOC, DTN, $\mathrm{NO}_{3}{ }^{-}$and $\mathrm{NH}_{4}{ }^{+}$in rhizosphere were higher than those in non-rhizosphere. On the contrary, the activity of dehydrogenase in rhizosphere was lower than that in non-rhizosphere $(P<0.05)$. Meanwhile, in aged-contaminated soils, ryegrass growth increased the content of DOC, DTN, $\mathrm{NO}_{3}{ }^{-}$and $\mathrm{NH}_{4}{ }^{+}$in the rhizosphere, but decreased those in the non-rhizosphere, as compared to the CK-Ry; while the activity of dehydrogenase showed almost the opposite trend. In freshly-spiked soils, regularity of the changes for these biochemical indexes was not exhibited. With respect to the iron content $\left(\mathrm{Fe}^{2+}\right.$ and $\left.\mathrm{Fe}^{3+}\right)$ and the catalase activity, there was almost no significant difference between rhizosphere and non-rhizosphere of both agedcontaminated and freshly-spiked soils. Additionally, the content of DOC was increased with the addition of compost, with the highest values achieved in the treatments of RyGC (112.1 and $101.9 \mathrm{mg} \cdot \mathrm{kg}^{-1}$ for aged-contaminated and freshlyspiked soils, respectively) (Table 3 ).

For rice group, in both aged-contaminated and freshlyspiked soils, the concentrations of DOC and DTN in rhizosphere were higher than those in non-rhizosphere, while the content of $\mathrm{NH}_{4}^{+}$in rhizosphere was lower than that in nonrhizospher; the addition of compost increased DOC and DTN values, as well as the activity of dehydrogenase and catalase, with the highest values of these biochemical indexes exhibited in the RiGC treatments of both aged-contaminated and freshly-spiked soils (Table 4).

The PCA of soil biochemical indexes was conducted to illustrate the treatments and rhizosphere effects in soils growing ryegrass and rice (Fig. 2). For the ryegrass group, rhizosphere and non-rhizosphere presented an obvious distinction between aged-contaminated or freshly-spiked soils. All the treatments in rhizosphere gathered together in

Table 2 The biomass of ryegrass and rice, and the concentration of BDE-209 in shoots and roots of ryegrass and rice grown in the contaminated soils.

\begin{tabular}{|c|c|c|c|c|c|}
\hline \multicolumn{2}{|c|}{ Treatments } & \multicolumn{2}{|c|}{ Root } & \multicolumn{2}{|c|}{ Shoot } \\
\hline & & \multirow{2}{*}{$\begin{array}{c}\text { Biomass } \\
(\mathrm{g})\end{array}$} & $\begin{array}{l}\text { BDE-209 } \\
\left(\mu \mathrm{g} \cdot \mathrm{kg}^{-1}\right)\end{array}$ & $\begin{array}{c}\text { Biomass } \\
\text { (g) }\end{array}$ & $\begin{array}{l}\text { BDE-209 } \\
\left(\mu \mathrm{g} \cdot \mathrm{kg}^{-1}\right)\end{array}$ \\
\hline \multirow[t]{8}{*}{ Aged-contaminated } & Ry & & $\mathrm{nd}^{\mathrm{b}}$ & $7.65 \pm 0.58$ & nd \\
\hline & RyG & $2.27 \pm 1.03$ & $154.6 \pm 12.6$ & $7.51 \pm 1.67$ & nd \\
\hline & RyC & $1.79 \pm 0.42$ & $96.2 \pm 8.5$ & $8.56 \pm 1.79$ & nd \\
\hline & RyGC & $1.78 \pm 0.13$ & nd & $9.50 \pm 1.04$ & nd \\
\hline & $\mathrm{Ri}$ & $1.62 \pm 0.68$ & nd & $9.72 \pm 4.09$ & nd \\
\hline & $\mathrm{RiG}$ & $3.46 \pm 0.64$ & nd & $10.71 \pm 1.58$ & nd \\
\hline & $\mathrm{RiC}$ & $3.44 \pm 0.85$ & nd & $13.48 \pm 1.98$ & nd \\
\hline & RiGC & $3.00 \pm 1.63$ & nd & $13.75 \pm 1.84$ & nd \\
\hline \multirow[t]{8}{*}{ Freshly-spiked } & Ry & $1.51 \pm 0.18$ & $495.9 \pm 48.5$ & $7.68 \pm 1.50$ & nd \\
\hline & RyG & $1.29 \pm 0.27$ & $482.9 \pm 25.7$ & $6.11 \pm 0.49$ & nd \\
\hline & RyC & $1.53 \pm 0.36$ & $437.7 \pm 77.2$ & $8.48 \pm 2.21$ & nd \\
\hline & RyGC & $1.57 \pm 0.55$ & $419.8 \pm 25.9$ & $7.12 \pm 1.63$ & $16.40 \pm 2.70$ \\
\hline & $\mathrm{Ri}$ & $1.18 \pm 0.35$ & $60.8 \pm 2.1$ & $8.80 \pm 1.01$ & nd \\
\hline & RiG & $1.83 \pm 0.41$ & $66.6 \pm 6.8$ & $12.42 \pm 2.50$ & nd \\
\hline & $\mathrm{RiC}$ & $5.87 \pm 1.60$ & $85.5 \pm 5.1$ & $16.79 \pm 2.23$ & nd \\
\hline & RiGC & $2.56 \pm 0.22$ & $76.6 \pm 4.7$ & $11.89 \pm 3.08$ & nd \\
\hline
\end{tabular}

Abbreviations for treatments are as Table 1; nd: not detected; Values are means \pm standard errors of three replications. 


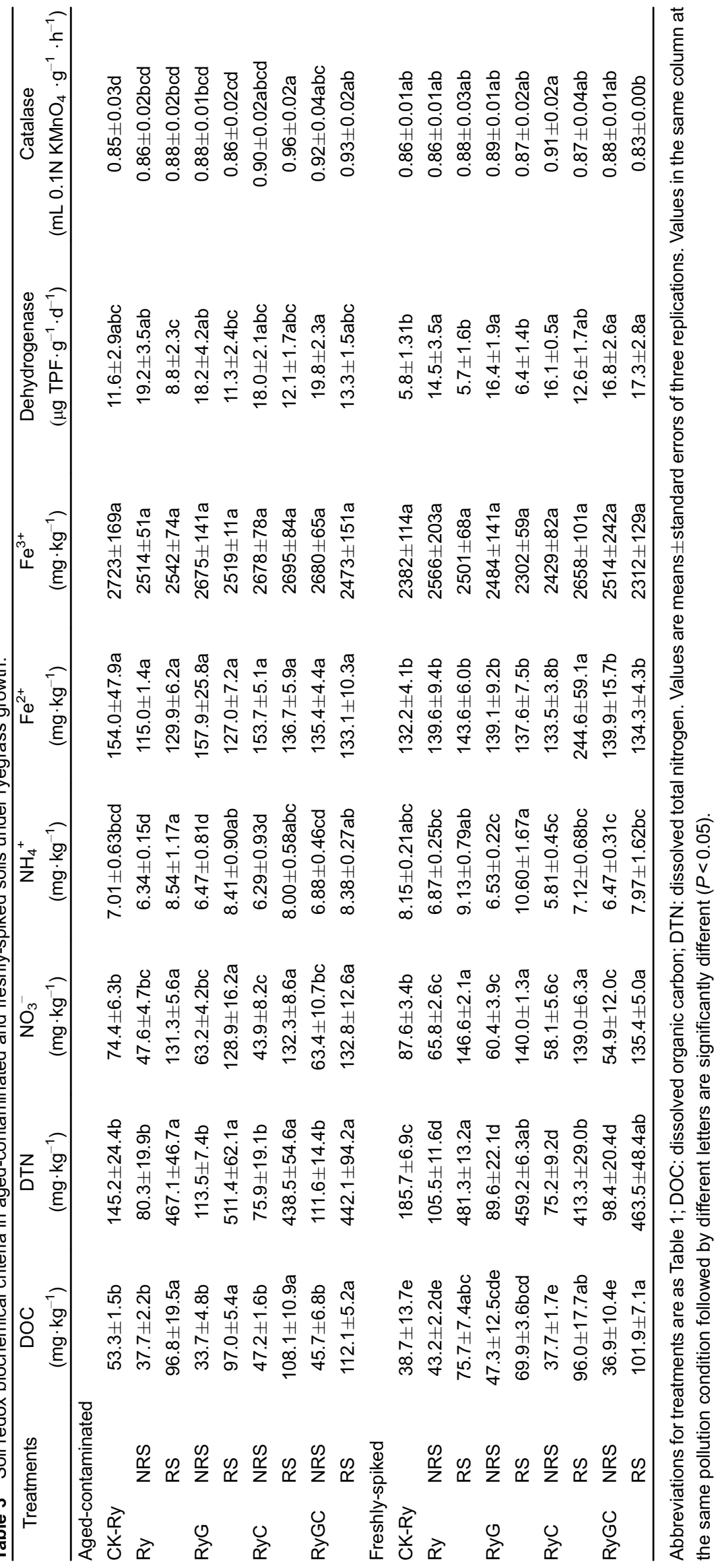




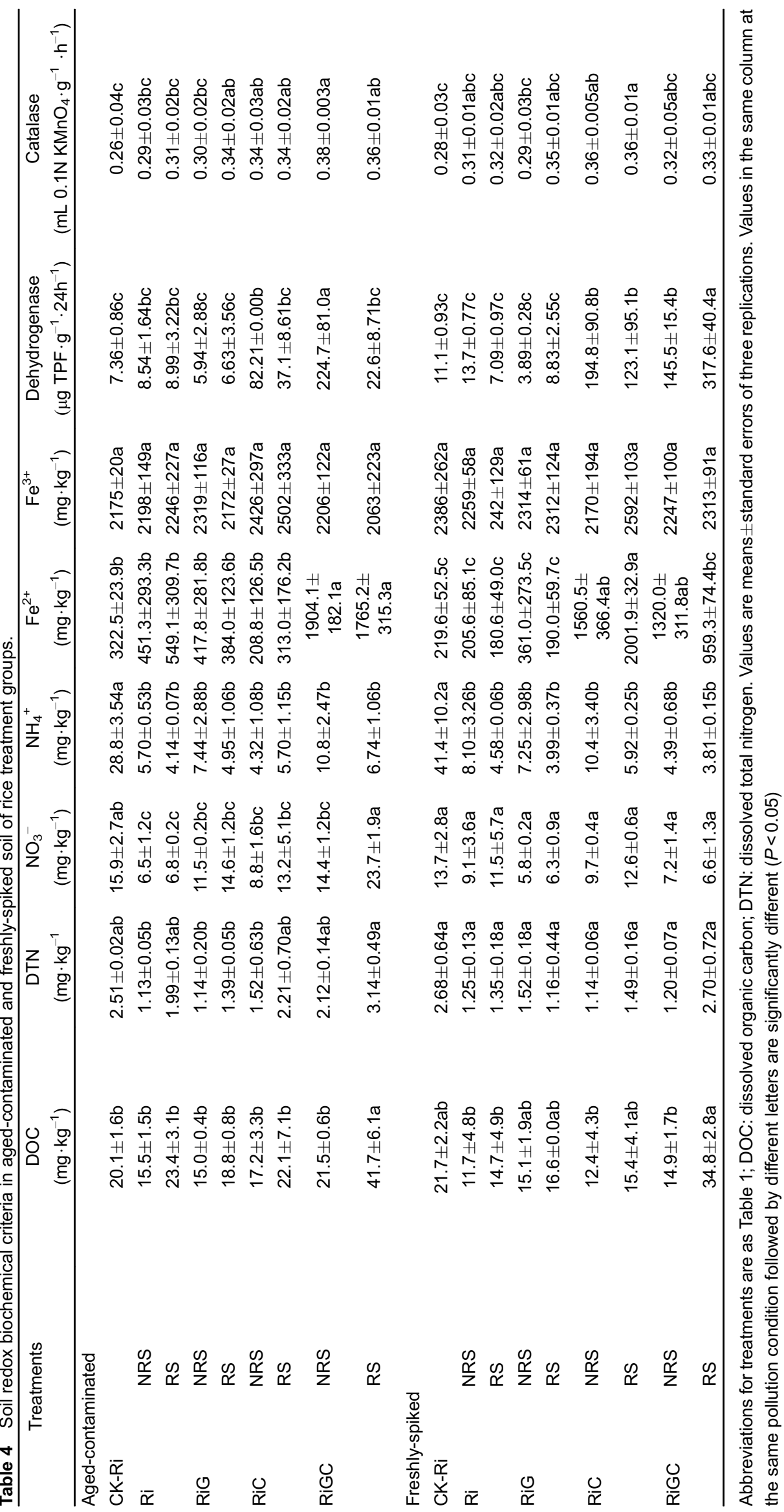


the positive axis of $\mathrm{PC} 1$, while those in non-rhizosphere plotted in the negative axis of PC1 (Fig. 2A and Fig. 2B). For the rice group, however, there was no difference among treatments of rhizosphere and non-rhizosphere in both agedcontaminated and freshly-spiked soils (Fig. 2B and 2D).

\subsection{Response of soil microbial community structure}

Soil microbial community structure as represented by the percentages of different bacterial groups in rhizosphere of ryegrass and rice at the phylum and order levels were shown in Fig. 3. A total of 28,527 and 40,270 effective sequences were obtained in the ryegrass and rice treatment groups, respectively. Proteobacteria and Actinobacteria were the most abundant phyla, accounting for $36.6 \%$ and $19.8 \%$ of the total gene sequences in soils under ryegrass, and $32.0 \%$ and $15.1 \%$ in soils with rice plants, respectively (Fig. $3 A$ and $3 C$ ); while Xanthomonadales and Actinomycetales dominated in the order levels, with $15.2 \%$ and $11.3 \%$ in soils of ryegrass group, and $12.3 \%$ and $8.5 \%$ in soils of rice group, respectively (Fig. 3B and 3D).

The growth of ryegrass simultaneously increased the

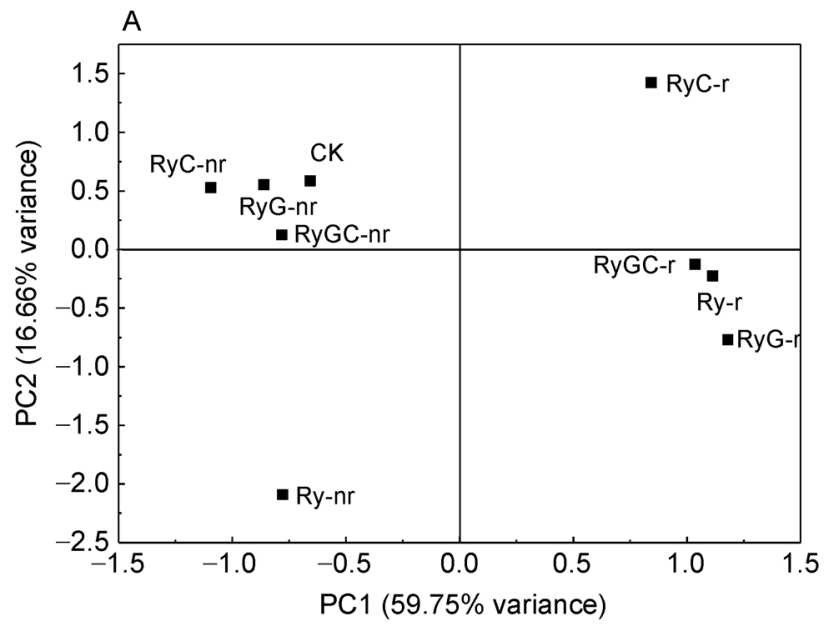

B

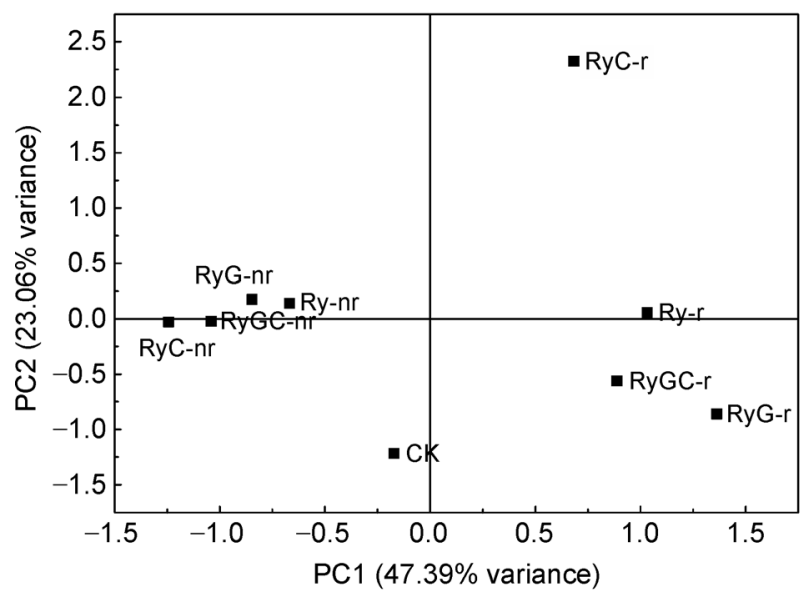

relative abundances of Proteobacteria, Actinobacteria and Bacteroidetes; and especially, the addition of compost improved the abundances of Bacteroidetes, Firmicutes, Gemmatimonadetes and Planctomycetes in both contaminated soils compared with those in the CK-Ry (Fig. 3A). The same tendency was found in all the AMF treatments, only with the exception of Firmicutes, with its abundance decreased following the inoculation of G. mosseae. At the order level, growing ryegrass increased the abundances of Actinomycetales, Saprospirales, Burkholderiales and Sphingomonadales. The amendment of compost clearly increased the abundances of Clostridiales, Cytophagales and Gemmatimonadales, but decreased that of Actinomycetales and Xanthomonadales. The inoculation of $G$. mosseae enhanced the abundances of Acidimicrobiales, Saprospirales, Gemmatales and Gemmatimonadales, with Gemmatimonadales only enriched in freshly-spiked soils (Fig. 3B).

Under rice growth, there was a certain difference in bacterial abundance at both the phylum and order levels among the treatments (Fig. 3C). The percentages of Proteobacteria and Gemmatimonadetes were slightly enhanced, but that of Bacteroidetes decreased in freshly-
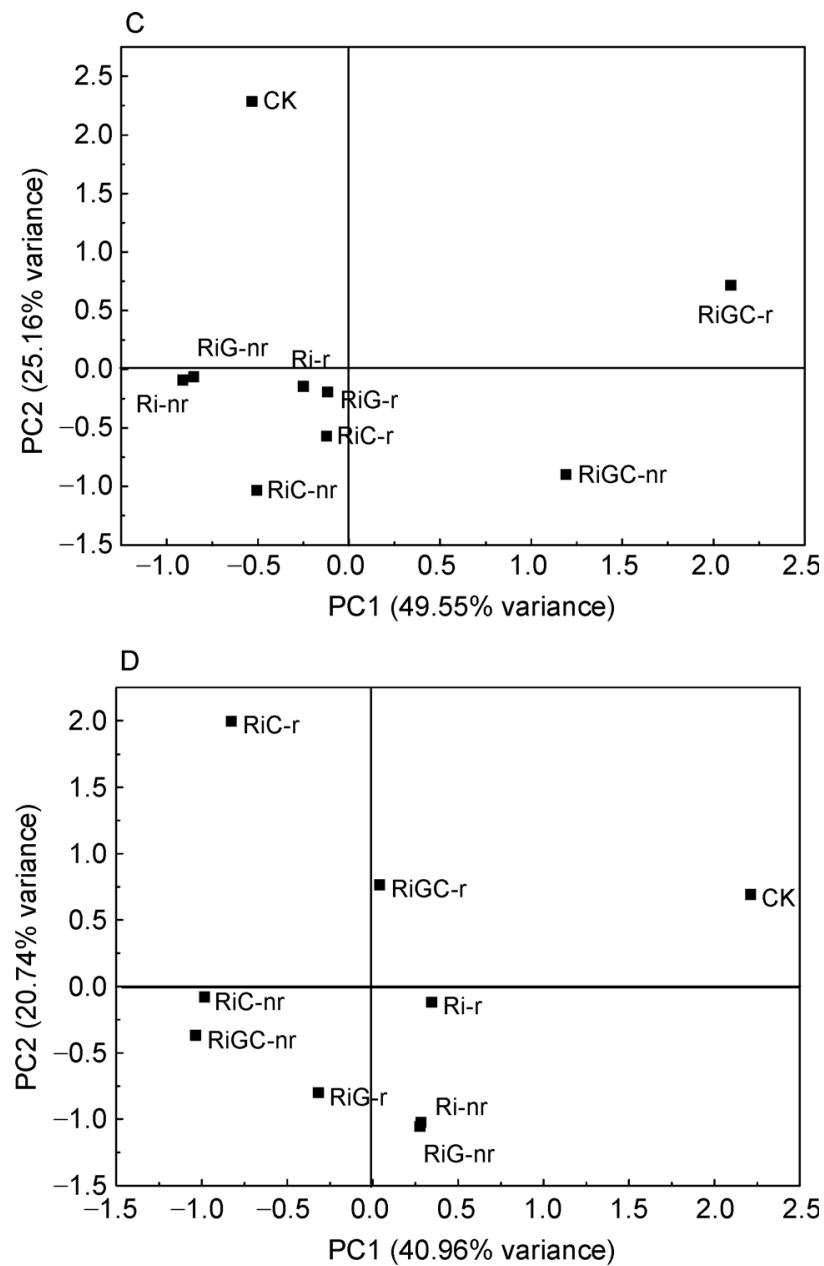

Fig. 2 Principal component analysis (PCA) based on the redox biochemical criteria of soils of ryegrass (A and $B)$ and rice (C and D) experiments (A and C: aged-contaminated soil; B and D: freshly-spiked soil; -nr: non-rhizosphere soil; -r: rihzosphere soil). 

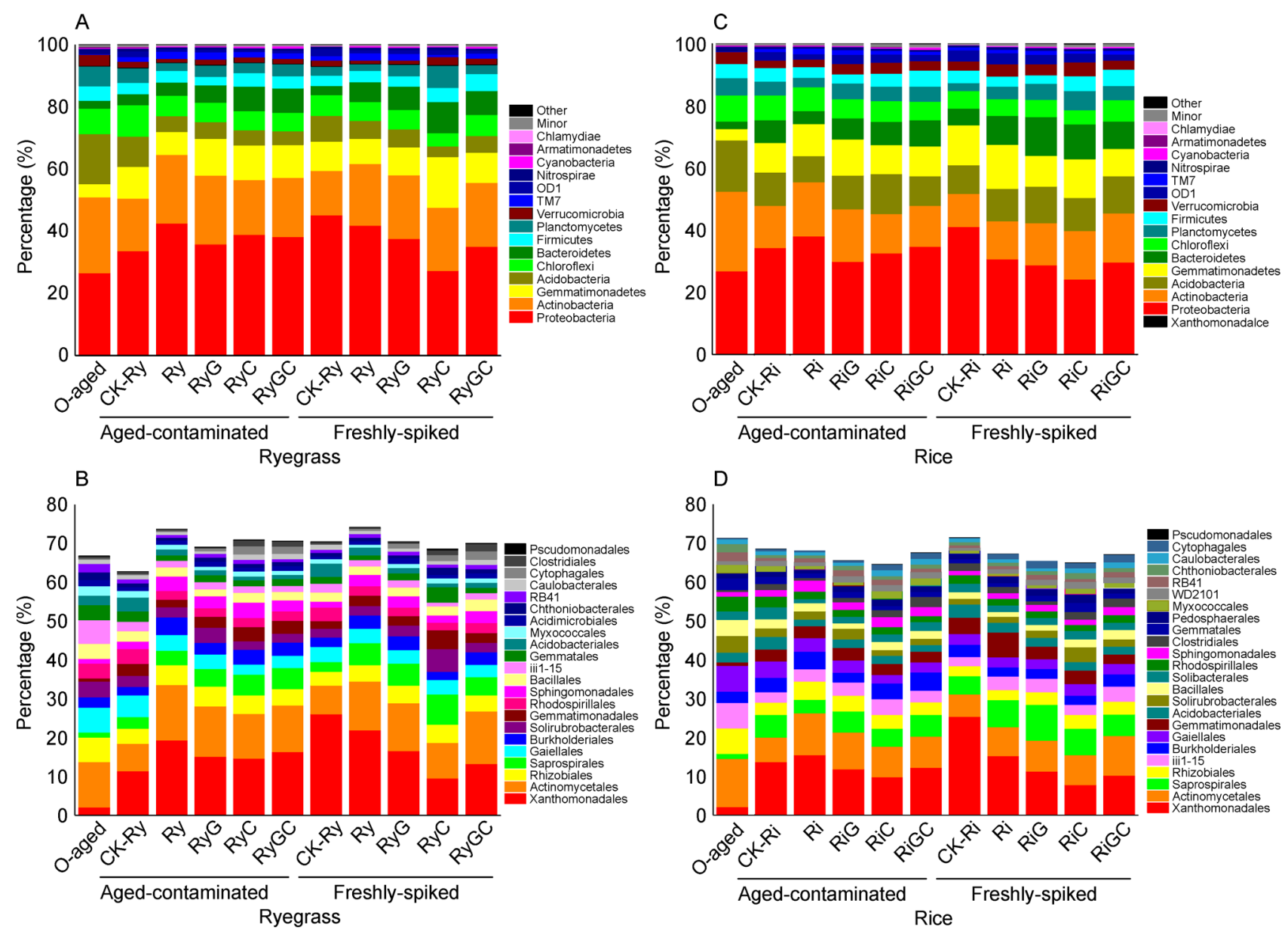

Fig. 3 Percentages of bacteria in rhizosphere soils of ryegrass $(A$ and $B)$ and rice $(C$ and $D)$ experiments $(A$ and $C$ : the major phyla; $B$ and $D$ : the major order). Abbreviations for treatments are as Table 1 and Fig. 1.

spiked soils. Although Xanthomonadales still dominated in bacteria community, it declined in the enhanced rhizoremediation treatments (RiG, RiC and RiGC), as compared to the treatment with rice only (Ri). Compost addition hardly altered the abundances of Clostridiales and Cytophagales, but enhanced the abundances of Bacteroidales, Anaerolineales and Myxococcales.

The first 20 bacterial taxa with most significant differences among the treatments $(P<0.05)$ was presented in Fig. 4. These taxa represented the sensitive responders among soil bacteria. Growing ryegrass enriched Flavisolibacter, Luteimonas and Gemmatimonas relative to the CK-Ry, with the greatest effect on Gemmatimonas that belongs to Gemmatimonadales. Additional amendment of compost and/or inoculation of G. mosseae enriched Adhaeribacter, Chthoniobacter, Flavisolibacter and Gemmatimonas. As for the rice group, the taxa abundance of microbial communities was much higher than that under ryegrass growth (Fig. 4). Among all the microbial communities, Acidothermus had the most abundance taxa, and was inhibited by rice growth as compared with that in the original soils. In contrast, Adhaeribacter was enriched in the treatments with additional amendment of compost and/or inoculation of G. mosseae, which showed the relatively high efficiency in BDE-209 dissipation during rice growth (Fig. 4B).

\subsection{Multivariate statistical analyses of bacteria data}

The RDA was further performed to visualize the relationships between the environment factors, the microbial communities and the treatments (Fig. 5). In the ryegrass group (Fig. 5A), the BDE-209 dissipation rate was correlated positively with the concentrations of DOC, DTN, $\mathrm{NO}_{3}{ }^{-}$and $\mathrm{NH}_{4}{ }^{+}$and the activity of catalase, but negatively with the concentrations of $\mathrm{Fe}^{3+}$. The DOC, DTN and $\mathrm{NO}_{3}{ }^{-}$were the major factors influencing bacterial community composition in the rhizosphere of the RyG treatments of aged-contaminated and of the RyGC treatment of freshly-spiked soils. In comparison, $\mathrm{NH}_{4}{ }^{+}$was the major factor in the Ry and RyG pf the aged-contaminated and the freshly-spiked soils, respectively. The activity of dehydrogenase and $\mathrm{Fe}^{2+}$ mostly affected the treatments with compost addition, including RyC of both polluted soils, and RyGC of aged-contaminated soils. By contrast, all the environment factors showed little influence on the CK-Ry 

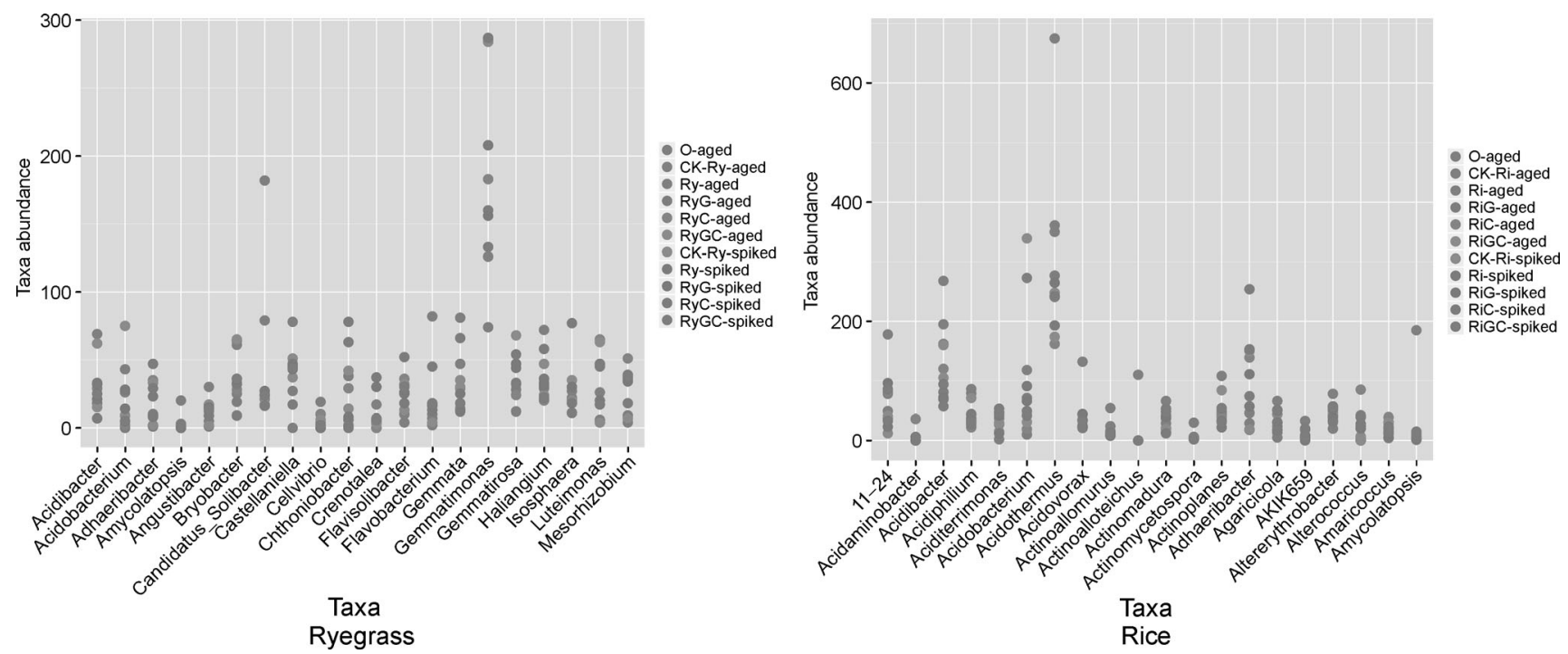

Fig. 4 The first 20 bacterial taxa with most significant differences among treatments $(P<0.05)$ in ryegrass $(A)$ and rice $(B)$ groups. Abbreviations for treatments are as Table 1 and Fig. 1 .
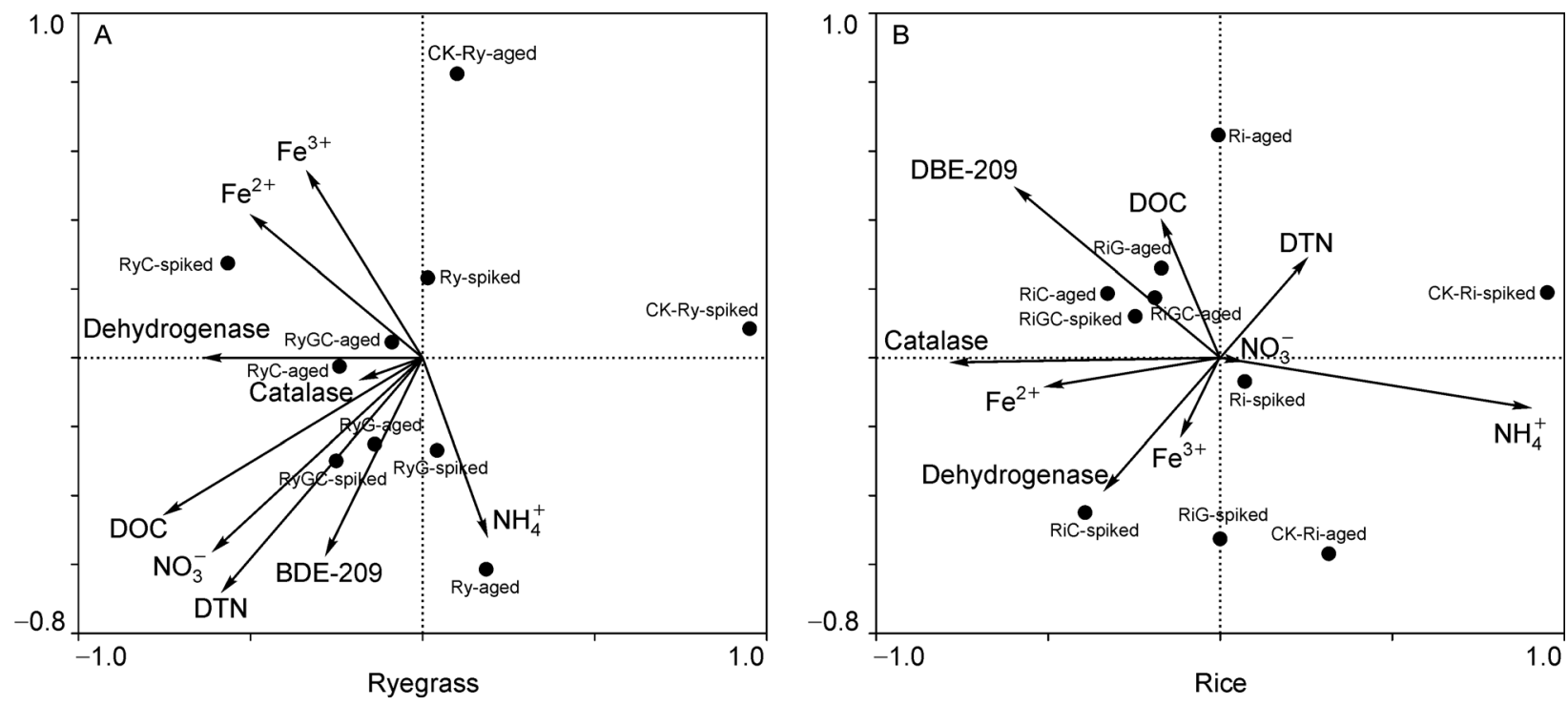

Fig. 5 Redundancy analysis (RDA) of the bacteria data with environmental variables in soils of ryegrass $(A)$ and rice $(B)$ experiments. Symbols: "BDE-209": BDE-209 dissipation rate percentage; " $\mathrm{Fe}^{2+}$, " $\mathrm{Fe}^{3+}$, , "DOC," "DTN," " $\mathrm{NO}_{3}{ }^{- \text {" }}$ and "NH ${ }_{4}^{+}$": Concentration of the $\mathrm{Fe}^{2+}$, $\mathrm{Fe}^{3+}, \mathrm{DOC}, \mathrm{DTN}, \mathrm{NO}_{3}{ }^{-}$and $\mathrm{NH}_{4}{ }^{+}$, respectively; "Dehydrogenase" and "Catalase": Activity of the dehydrogenase and catalase, respectively. Abbreviations for treatments are as Table 1 and Fig. 1.

treatments of both polluted soils, and in the Ry treatment of freshly-spiked soils. In the rice group (Fig. 5B), the BDE-209 dissipation rate was positively correlated with the concentrations of $\mathrm{DOC}$ and $\mathrm{Fe}^{2+}$ and the activity of catalase, but negatively with the concentration of $\mathrm{NH}_{4}{ }^{+}$. The concentration of DOC and the activity of catalase were the main factors influencing bacterial community composition in rhizosphere of the RiC, RiG and RiGC treatments of aged-contaminated soil, and of the RiGC of freshly-spiked soil. The activity of dehydrogenase influenced the freshly-spiked RiC, and the concentration of $\mathrm{NH}_{4}{ }^{+}$influenced the freshly-spiked $\mathrm{Ri}$. However, bacterial communities of the aged-contaminated
CK-Ri, and the freshly-spiked CK-Ri and RiG treatments were little affected by all the environment factors.

\section{Discussion}

\subsection{Dissipation process of BDE-209 in soils and plants}

Plants can enhance the dissipation of OCs by various processes, like immobilization, removal, and promotion of microbial degradation (Megharaj et al., 2011). In our study, the BDE-209 removal was verified to be dependent on plant species, pollution condition and agronomic practices, and 
between rhizosphere and non-rhizosphere (Table 1 and Fig. 1). There was no BDE-209 detected in shoots of the plants grown in aged-contaminated soils, and only fewer BDE-209 was found in shoots of the plants grown in freshlyspiked soils, with the accumulated amount less than the millesimal of total amount in the system (Table 2). This result was in accordance with the previous reports showing that plants (e.g. ryegrass) could take up and accumulate BDE-209 from contaminated soils but had a low root-to-shoot translocation efficiency (Huang et al., 2010; Xie et al., 2013). Meanwhile, the amount accumulated by the roots of ryegrass $(0.68$ $\mu \mathrm{g}$ in total, calculated based on Table 2) was over three times greater than that by rice $(0.22 \mu \mathrm{g}$ in total, calculated based on Table 2) in the freshly-spiked treatments (Table 2). Although the contribution of plants through root uptake for depletion of BDE-209 was limited, the results suggest that the ryegrass has higher uptake capacity than the rice, and that the translocation efficiency of BDE-209 from soil to root and further to shoot depends on plant species, pollutant conditions and agronomic practices (Huang et al., 2010; Xie et al., 2013). Besides, the addition of compost and/or AMF decreased the root uptake efficiency. This was likely due to their effect in promoting rhizospheric dissipation of BDE-209 in the soils.

As previously reported, plants have a range of advantages in the dissipation of PBDEs including BDE-209 in soils (Huang et al., 2010; Wang et al., 2014; He et al., 2015), and the dissipation of OCs varied with its proximity to the roots (He et al., 2005, 2009; Wang et al., 2011a). Our results showed that regardless of plant species (ryegrass and rice), the concentration of BDE-209 was lower in rhizosphere than in nonrhizosphere in all treatments, but the difference was only significant in the aged-contaminated soils growing ryegrass (Table 1 and Fig. 1). As shown by the PCA results of Fig. 2, the rhizosphere and non-rhizosphere soils under ryegrass were significantly separated in different clusters (Fig. $2 \mathrm{~A}$ and $2 \mathrm{~B}$ ); and additional amendment of compost and/or AM fungal inoculation enhanced the dissipation of BDE-209 to a greater extent in rhizosphere than in non-rhizosphere (Table 1). A synergistic effect of AMF and plant rhizosphere in improving the dissipation of pentachlorinated biphenyls was also verified previously (Qin et al., 2014). In comparison, there was no obvious distinction between rhizosphere and non-rhizosphere soils under rice plants, with the only exception of the discrete rhizosphere soils of RiGC treatment that exhibited the highest removal rate of BDE-209 (Fig. 2A and 2B). Different cluster effects for rhizosphere and non-rhizosphere soils between ryegrass and rice groups suggest that the rhizosphere effect was greater in ryegrass than in rice. This might be ascribed to specific plant types and associated microbial communities around plant roots (Wang et al., 2011a; Qin et al., 2014). Smaller rhizosphere effect of rice as shown by the little difference in BDE-209 depletion between rhizosphere and non-rhizosphere during rice growth might also be ascribed to the radial oxygen release function of rice root, which might lead to changes in anaerobic status, thereby reduced the debromination intensity in rice root surroundings and thus partly offset the positive effect of rice root exudates in facilitating BDE-209 removal.

In the rice group, simultaneous inoculation of $G$. mosseae and addition of compost facilitated the dissipation of BDE-209 mostly in both aged-contaminated and freshly-spiked soils (an average removal of $38.9 \%$ for RiGC). On the contrary, in the ryegrass treatment group, simultaneous addition of compost with $G$. mosseae inoculation decreased the dissipation rate of BDE-209 (an average removal of $18.2 \%$ for RyGC), as compared to the highest removal treatment with only $G$. mosseae inoculation in both aged-contaminated and freshlyspiked soils (an average removal of $34.5 \%$ for RyG) (Table 1 and Fig. 1). This suggests that the improved remediation effect through different agronomic practices (in this case, e.g. only inoculation with $G$. mosseae, or simultaneous addition of compost and inoculation of G. mosseae) is plant-species specific.

Differences in hygrophilous and xerophilous species would generate a contrasting anaerobic or aerobic effect, thereby altering the rhizospheric dissipation response of BDE-209 following addition of compost and inoculation of AMF. Usually, compost can offer large amounts of nutrients during plant growth, so it improves the growth of plant and increases soil microbial activities, so as to enhance remediation efficiency (Walker et al., 2004). Kästner et al. (1995) observed that the addition of mature compost accelerated the depletion of hydrocarbons because of the facilitated microbial mineralization and the formation of non-extractable bound residues. Cheng and Wong (2008) also showed the application of pig manure compost enhanced the removal of pyrene. Anaerobic composting with pig manure accelerated the dechlorination of PCB in the contaminated soil (Zhang et al., 2013), which may support our results regarding the efficiency in BDE-209 dissipation in the rice treatments with compost addition. In our study, under aerobic soil condition during the growth of ryegrass, addition of compost might increase the respiratory metabolism of aerobes, thereby consuming most of the oxygen so as to inhibit the aerobic degradation of BDE-209 partly. Meanwhile, the addition of compost under aerobic soil condition might facilitate the transformation of BDE-209 from un-extractable to extractable residues, thereby increasing the proportion of the extractable BDE-209 so as to reduce the apparent dissipation rate that was calculated on the basis of extractable amount. Additionally, the dissipation rates of BDE209 were higher in the G. mosseae-inoculated treatments in comparison with the corresponding non-mycorrhizal treatments under both ryegrass and rice, especially under the growth of ryegrass in aged-contaminated soils that exhibited significant difference (Table 1 and Fig. 1). The similar findings have also been reported previously. For example, Kuo et al. (2014) found the B. pilosa inoculated with G. mosseae was able to increase degradation of petroleum hydrocarbons by $9 \%$ in soils after 64 days. Qin et al. (2014) showed that AMF could enhance bph gene abundance and the growth of specific bacterial groups so as to enhance PCB dissipation.

As for the dissipation differences in pollution doses, 
Megharaj et al. (2011) suggested that the toxicity of pollutants on plant growth was concentration-dependent, with the effects differing among plant species. Our results revealed that the removal rates of BDE-209 in the low pollution condition (agedcontaminated soils) were higher than those in high pollution condition (freshly-spiked soils) for both plant species (Table 1 and Fig. 1). In particular, no significant differences in BDE-209 dissipation rates between rhizosphere and non-rhizosphere were exhibited either in ryegrass or rice groups in freshlyspiked soils. Possible reasons might be lie on: First, the indigenous microbes had already been adapted to BDE-209 stress of low concentration in aged-contaminated soils, while they might be still suffering from BDE-209 stress of high concentration when freshly spiked into the soils. Secondly, the rapid degradation rate by soil microorganisms and assimilation proportion by plants under low pollution stress (He et al., 2015). In addition, the relatively high pollution stress inhibited the growth of plant (as evidence by decrease in the plant biomass of freshly-spiked soils relative to that of agedcontaminated soils, Table 2), thereby diminished the rhizosphere effect. Furthermore, the relatively high pollution stress inhibited some microbial growth and thus decrease the abundant of the microbial communities;

Besides the influence of plant growth, environment factors can also influence the microbial communities and thereby the removal of BDE-209. It was revealed that DOC usually acts as electron donors whereas $\mathrm{NO}_{3}^{-}$and $\mathrm{Fe}^{3+}$ as electron acceptors participating in the microbial dehalogenated respiration (Kotik et al., 2013; Xu et al., 2014, 2015; He et al., 2015). He et al. (2015) found that both $\mathrm{NO}_{3}^{-}$and $\mathrm{Fe}^{3+}$ inhibited BDE-209 dissipation in either rhizosphere or nonrhizosphere, of which $\mathrm{NO}_{3}{ }^{-}$affected more significantly than $\mathrm{Fe}^{3+}$. Our results indicate that in aerobic conditions, $\mathrm{Fe}^{3+}$ inhibited BDE-209 dissipation in all treatments, while $\mathrm{NH}_{4}^{+}$ increased BDE-209 dissipation, especially in the treatments with G. mosseae inoculation (Fig. 5). Redundancy analysis indicated that in anaerobic conditions, both $\mathrm{NO}_{3}{ }^{-}$and $\mathrm{NH}_{4}{ }^{+}$ could inhibit BDE-209 dissipation, while other environmental factors showed a promoted effect (Fig. 5). This was likely ascribed to the competitive consumption of available electron donors by $\mathrm{NO}_{3}{ }^{-}$and $\mathrm{Fe}^{3+}$ splitting the electron to denitrification and iron reduction instead of dehalogenation (Xu et al., 2015, 2017; Xue et al., 2017), thereby suppressed the depletion of BDE-209 through reductive debromination. In addition, a striking similarity between PBDEs and other halogenated compounds (e.g. PCBs) about dehalogenation studies was observed in previous studies (Gerecke et al., 2005; He et al., 2006; Robrock et al., 2009). Plants could bring in many nutrients which were beneficial for development of microbes, thus enhancing the dissipation of BDE-209. The DOC, DTN and the activity of catalase and dehydrogenase had the abilities to enhance dissipation of BDE-209, with the influence of DOC as the relatively important factor in all treatments (Tables 3 and 4, and Fig. 5). The catalase was usually found in aerobic bacteria and most facultative anaerobes but absent in obligate anaerobes (Shiyin et al., 2004), consistent with our study that the catalase was more active in soils growing ryegrass than growing rice plants. A previous study revealed that the dehydrogenase was an enzyme capable of influencing soil's microbial activity and the dissipation rate of BDE-209 (García-Orenes et al., 2010; He et al., 2015). According to our results, compost addition increased the activity of dehydrogenase $(P<0.05)$, suggesting that compost addition might be an important source of dehydrogenase, thereby further affecting the reductive debromination process of BDE-209.

\subsection{Changes of microbial communities during BDE-209 removal}

To develop effective remediation strategies for contaminated soils requires detailed understanding regarding the microbial community responses to changes during remediation processes. In our study, microbiota in the rhizosphere of both ryegrass and rice were dominated by the phyla of Proteobacteria, Actinobacteria and Gemmatimonadetes, represented by the taxa related to Xanthomonadales, Actinomycetales and Gemmatimonadales in both treatment groups (Fig. 3). And the top phyla in rhizosphere included Proteobacteria, Actinobacteria, Acidobacteria, Gemmatimonadetes, Bacteroidetes, Firmicutes, Chloroflexi and Planctomycetes (Fig. $3 \mathrm{~A}$ and $3 \mathrm{C}$ ). These were previously verified as the members that made up most of the bacterial diversity of soil microbiota (Edwards et al., 2015). At the order level, Actinomycetales, Burkholderiales and Sphingomonadales were enriched in the efficient BDE-209 dissipation treatments in both ryegrass and rice groups (Fig. 3B and 3D). This revealed the possibility of these microbial groups regarding their potential of survival and persistance under the pollution stress of BDE-209 or even capable of stimulating the removal of BDE-209 during plant growth (Fig. 3). Previous studies also revealed that Actinomycetales, Burkholderiales, Sphingomonadales and Xanthomonadales were dominated at the order level in PCB- or PAH-contaminated soils (Bourceret et al., 2016; Qin et al., 2016; Festa et al., 2016). Their consistently enriched response under ryegrass and rice growth suggested that they might work in a synergetic way for BDE-209 removal. At the detectable genus level, Rhodanobacter was one of the most abundant microbial group in all treatments, especially in the rice group. This genus has been previously reported with an ability to persist in the polluted niche due to its ability to acquire carbon from OCs (Uhlik et al., 2012) and has been verified to be associated with the degradation of PAHs, chlorobenzoates, or certain pesticides, benzoate directly in soils (Gentry et al., 2004; Uhlik et al., 2012). Meanwhile, previous studies have verified that the genera of Sphingomonas (Kim et al., 2007), Burkholderia, Rhodococcus (Robrock et al., 2009) and Lysinibacillus (Deng et al., 2011) that belong to the dominant orders mentioned above were capable of degrading PBDEs. However, there were no significant enrichment exhibited by these genera in our study. This might be due to differences in soil type and indigenous microbial community structure. 
Besides the change of microbial communities induced by ryegrass and rice growth, inoculation of G. mosseae and/or compost addition under different pollution conditions during plant growth also jointly influenced the rhizosphere microbiota. The treatments with $G$. mosseae inoculation and/or compost addition affected a number of bacterial orders in the soils, including Acidobacteriales, Actinomycetales, Clostridiales, Sphingomonadales, Cytophagales, Gemmatimonadales, Xanthomonadales and Saprospirales. The similar phenomena were also observed in early studies (Nissilä et al., 2011; Schmalenberger et al., 2013; Hervé et al., 2014; Shabarova et al., 2014; Krustok et al., 2015). The Actinomycetales and Xanthomonadales were significantly abundant in the treatments with compost and G. mosseae, representing over the one fourth of total microbial communities (Fig. 3). Xanthomonadales was extensively identified in planted soils, wood substrate and sediments (Aslam et al., 2009; Hervé et al., 2014; Schmalenberger et al., 2013) and was stimulated during vermicomposting and might be capable of enhancing the PCP biodegradation in soil (Lin et al., 2016). Our results also showed that the bacteria in the orders of Actinomycetale, Clostridiales, Sphingomonadales and Cytophagales enriched in the treatments with compost (Fig. 3). Nissilä et al. (2011) revealed that Clostridiaceae (Clostridiales) was mainly responsible for hydrogen production and cellulose degradation in compost-enrichment cultures. Clostridiales and Actinomycetales could both contribute to the formation of communities in the thermophilic stages of composting and secrete bacterial enzymes to enhance deconstruction of recalcitrant lignocellulose during composting process (Martins et al., 2013). Cytophagaceae (Cytophagales) OTUs were related to different anaerobic conditions, which were also the main determinants of dissolved organic matter composition (Shabarova et al., 2014). Adhaeribacter that belongs to Cytophagaceae was detected as the significant different taxa $(P<0.05)$ in both ryegrass and rice treatment groups, and was enriched in compost and/or AMF inoculation treatments (Fig. 4). Obviously, it was influenced by the agronomic practices and might be conducive to the dissipation of BDE209. It was reported that Adhaeribacter was a generator of large amounts of extracellular fibrillar material, a concrete corrosion agent that was able to degrade polymers (Zhang et al., 2009; Li et al., 2012; Aislabie et al., 2013). Therefore, it could be a specialized genus in the degradation of complex products derived from different composts (Calleja-Cervantes et al., 2015). The genus of Gemmatimonas which was actively involved in the growth of ryegrass had been reported to be a cellulolytic bacterium (Guo et al., 2016) and might play important roles in regulating SOC dynamics (Wang et al., 2017). Actinomycetales, Gemmatimonadetes and Saprospirales were more abundant in the G. mosseae inoculation treatments compared with that with plants only. Qin et al. (2014) revealed that the Rhodococcus (Actinomycetales)-like bphC gene might play an important role in PCB dissipation in the presence of AMF and the removal process in the AMinoculated treatments might be attributed to the exudates secreted by AM hyphae, which could act as both nutrients and inducers on soil rhizobia.

We speculated that 1) the members of Actinomycetales, Burkholderiales, Sphingomonadales and Xanthomonadales might be the sensitive responders in BDE-209-contaminated soils during rhizoremediation, and even the active participants in facilitating the removal of BDE-209 from polluted soils; and 2) agronomic practices such as G. mosseae inoculation and/ or compost addition further enriched the functional bacterial groups of Clostridiales, Cytophagales, Gemmatimonadales and Saprospirales, thereby improved rhizoremediation during the growth of ryegrass or rice.

4.3 Implication for a strengthened rhizoremediation of BDE209 polluted farmland soil in typical E-waste dismantling areas

BDE-209 was relatively stable due to its completely brominated character, so as that anaerobic reductive debromination is a crucial step for its degradation (He et al., 2015). As verified by the relevant previous studies, an initial reductive dehalogenation and subsequent oxidative cleavage of aromatic ring and complete mineralization would be an effective way for facilitating the degradation process of highly halogenated compounds that have a very stable structure (He et al., 2015; Arslan et al., 2017; Vergani et al., 2017). The removal of halogen atoms decreases hydrophobicity of the highly halogenated compounds and makes their aromatic ring more susceptible to be cleaved, thereby facilitating the subsequent aerobic complete mineralization (Ghattas et al., 2017). It was thus speculated that regulating soil redox status by sequential wetting-drying management can improve the remediation effect of BDE-209-contaminated soil due to the anaerobic-aerobic alternate soil habitat that could induce increased BDE-209 depletion through initial microbial reductive debromination to lesser brominated congeners first, and then followed by aerobic oxidative cleavage of benzene ring. Therefore, a multi-stage treatment process was proposed to remit soil BDE-209 pollution around e-waste dismantling areas using sequentially rice and ryegrass plantation coupling with relevant agronomic measures including AMF inoculation and/or compost addition.

\section{Conclusion}

By combining with G. mosseae inoculation and/or compost addition, the removal of BDE-209 in soils growing ryegrass or rice was greatly improved, with the effect regulated by the plant-microbial interactions that depended on plant species and pollution conditions. A multi-stage treatment process was proposed to remit soil BDE-209 pollution around e-waste dismantling areas using sequentially rice and ryegrass plantation coupling with relevant agronomic measures including AMF inoculation and/or compost addition.

\section{Acknowledgments}

This work was jointly supported by the National Natural Science 
Foundation of China (41721001, 41771269, 41322006), the National Key Research and Development Program of China (2016YFD0800207), and the 111 Project (B17039).

\section{References}

Ahn, M.Y., Filley, T.R., Jafvert, C.T., Nies, L., Hua, I., Bezares-Cruz, J., 2006. Photodegradation of decabromodiphenyl ether adsorbed onto clay minerals, metal oxides, and sediment. Environmental Science \& Technology 40, 215-220.

Aislabie, J.M., Lau, A., Dsouza, M., Shepherd, C., Rhodes, P., Turner, S.J., 2013. Bacterial composition of soils of the Lake Wellman area, Darwin Mountains, Antarctica. Extremophiles 17, 775-786.

Arslan, M., Imran, A., Khan, Q.M., Afzal, M., 2017. Plant-bacteria partnerships for the remediation of persistent organic pollutants. Environmental Science and Pollution Research International 24, 4322-4336.

Aslam, Z., Park, J.H., Kim, S.W., Jeon, C.O., Chung, Y.R., 2009. Arenimonas oryziterrae sp. nov., isolated from a field of rice (Oryza sativa L.) managed under a no-tillage regime, and reclassification of Aspromonas composti as Arenimonas composti comb. nov. International Journal of Systematic and Evolutionary Microbiology 59, 2967-2972.

Bizkarguenaga, E., Iparraguirre, A., Oliva, E., Quintana, J.B., Rodil, R., Fernández, L.A., Zuloaga, O., Prieto, A., 2016. Uptake of polybrominated diphenyl ethers by carrot and lettuce crops grown in compost-amended soils. Environmental Science and Pollution Research International 23, 3847-3859.

Bourceret, A., Cébron, A., Tisserant, E., Poupin, P., Bauda, P., Beguiristain, T., Leyval, C., 2016. The bacterial and fungal diversity of an aged PAH- and heavy metal-contaminated soil is affected by plant cover and edaphic parameters. Microbial Ecology 71, 711724.

Calleja-Cervantes, M.E., Menéndez, S., Fernández-González, A.J., Irigoyen, I., Cibriáin-Sabalza, J.F., Toro, N., Aparicio-Tejo, P.M., Fernández-López, M., 2015. Changes in soil nutrient content and bacterial community after 12 years of organic amendment application to a vineyard. European Journal of Soil Science 66, 802-812.

Chen, J., Zhou, H.C., Wang, C., Zhu, C.Q., Tam, N.F., 2015. Shortterm enhancement effect of nitrogen addition on microbial degradation and plant uptake of polybrominated diphenyl ethers (PBDEs) in contaminated mangrove soil. Journal of Hazardous Materials 300, 84-92.

Cheng, K.Y., Wong, J.W.C., 2008. Fate of 14C-Pyrene in soil-plant system amended with pig manure compost and Tween 80: a growth chamber study. Bioresource Technology 99, 8406-8412.

Dai, Z., Hu, J., Xu, X., Zhang, L., Brookes, P.C., He, Y., Xu, J., 2016. Sensitive responders among bacterial and fungal microbiome to pyrogenic organic matter (biochar) addition differed greatly between rhizosphere and bulk soils. Scientific Reports 6, 36101.

Deng, D., Liu, J., Xu, M., Zheng, G., Guo, J., Sun, G., 2016. Uptake, translocation and metabolism of decabromodiphenyl ether (BDE209) in seven aquatic plants. Chemosphere 152, 360-368.

Deng, D.Y., Guo, J., Sun, G.P., Chen, X.J., Quu, M.D., Xu, M.Y., 2011 Aerobic debromination of deca-BDE: Isolation and characteriza- tion of an indigenous isolate from a PBDE contaminated sediment. International Biodeterioration \& Biodegradation 65, 465-469.

Dong, Y., Li, L., Bie, P., Jia, S., Wang, Q., Huang, Z., Qiu, X., Zhang, J., $\mathrm{Hu}$, J., 2014. Polybrominated diphenyl ethers in farmland soils: source characterization, deposition contribution and apportionment. Science of the Total Environment 466-467, 524-532.

Edwards, J., Johnson, C., Santos-Medellín, C., Lurie, E., Podishetty, N.K., Bhatnagar, S., Eisen, J.A., Sundaresan, V., 2015. Structure, variation, and assembly of the root-associated microbiomes of rice. Proceedings of the National Academy of Sciences of the United States of America 112, E911-E920.

Festa, S., Macchi, M., Cortés, F., Morelli, I.S., Coppotelli, B.M., 2016. Monitoring the impact of bioaugmentation with a $\mathrm{PAH}$-degrading strain on different soil microbiomes using pyrosequencing. FEMS Microbiology Ecology 92, w125.

García-Orenes, F., Guerrero, C., Roldán, A., Mataix-Solera, J., Cerdà, A., Campoy, M., Zornoza, R., Bárcenas, G., Caravaca, F., 2010. Soil microbial biomass and activity under different agricultural management systems in a semiarid Mediterranean agroecosystem. Soil \& Tillage Research 109, 110-115.

Gentry, T.J., Wang, G., Rensing, C., Pepper, I.L., 2004. Chlorobenzoate-degrading bacteria in similar pristine soils exhibit different community structures and population dynamics in response to anthropogenic 2-, 3-, and 4-chlorobenzoate levels. Microbial Ecology 48, 90-102.

Gerecke, A.C., Hartmann, P.C., Heeb, N.V., Kohler, H.P., Giger, W., Schmid, P., Zennegg, M., Kohler, M., 2005. Anaerobic degradation of decabromodiphenyl ether. Environmental Science \& Technology 39, 1078-1083.

Ghattas, A.K., Fischer, F., Wick, A., Ternes, T.A., 2017. Anaerobic biodegradation of (emerging) organic contaminants in the aquatic environment. Water Research 116, 268-295.

Guo, L., Zheng, S., Cao, C., Li, C., 2016. Tillage practices and strawreturning methods affect topsoil bacterial community and organic $C$ under a rice-wheat cropping system in central China. Scientific Reports 6, 33155.

Hayat, T., Ding, N., Ma, B., He, Y., Shi, J., Xu, J., 2011. Dissipation of pentachlorophenol in the aerobic-anaerobic interfaces established by the rhizosphere of rice (Oryza sativa L.) root. Journal of Environmental Quality 40, 1722-1729.

He, J., Robrock, K.R., Alvarez-Cohen, L., 2006. Microbial reductive debromination of polybrominated diphenyl ethers (PBDEs). Environmental Science \& Technology 40, 4429-4434.

He, Y., Li, X., Shen, X., Jiang, Q., Chen, J., Shi, J., Tang, X., Xu, J., 2015. Plant-assisted rhizoremediation of decabromodiphenyl ether for e-waste recycling area soil of Taizhou, China. Environmental Science and Pollution Research International 22, 99769988.

He, Y., Xu, J.M., Lv, X.F., Ma, Z.H., Wu, J.J., Shi, J.C., 2009. Does the depletion of pentachlorophenol in root-soil interface follow a simple linear dependence on the distance to root surfaces? Soil Biology \& Biochemistry 41, 1807-1813.

He, Y., Xu, J.M., Tang, C.X., Wu, Y.P., 2005. Facilitation of pentachlorophenol degradation in the rhizosphere of ryegrass (Lolium perenne L.). Soil Biology \& Biochemistry 37, 2017-2024.

He, Y., Xu, J.M., Ma, Z.H., Wang, H.Z., Wu, Y.P., 2007. Profiling of 
PLFA: Implications for nonlinear spatial gradient of PCP degradation in the vicinity of Lolium perenne L. roots. Soil Biology \& Biochemistry 39, 1121-1129.

Hervé, V., Le Roux, X., Uroz, S., Gelhaye, E., Frey-Klett, P., 2014. Diversity and structure of bacterial communities associated with Phanerochaete chrysosporium during wood decay. Environmental Microbiology 16, 2238-2252.

Huang, H., Zhang, S., Christie, P., Wang, S., Xie, M., 2010. Behavior of decabromodiphenyl ether (BDE-209) in the soil-plant system: uptake, translocation, and metabolism in plants and dissipation in soil. Environmental Science \& Technology 44, 663-667.

Huang, L., Zhuo, J., Guo, W., Spencer, R.G.M., Zhang, Z., Xu, J., 2013. Tracing organic matter removal in polluted coastal waters via floating bed phytoremediation. Marine Pollution Bulletin 71, 74-82.

Inui, H., Wakai, T., Gion, K., Yamazaki, K., Kim, Y.S., Eun, H., 2011. Congener specificity in the accumulation of dioxins and dioxin-like compounds in Zucchini plants grown hydroponically. Bioscience, Biotechnology, and Biochemistry 75, 705-710

Kästner, M., Lotter, S., Heerenklage, J., Breuer-Jammali, M., Stegmann, R., Mahro, B., 1995. Fate of 14C-labeled anthracene and hexadecane in compost-manured soil. Applied Microbiology and Biotechnology 43, 1128-1135.

Kim, Y.M., Nam, I.H., Murugesan, K., Schmidt, S., Crowley, D.E., Chang, Y.S., 2007. Biodegradation of diphenyl ether and transformation of selected brominated congeners by Sphingomonas sp. PH-07. Applied Microbiology and Biotechnology 77, 187-194.

Kotik, M., Davidová, A., Voříšková, J., Baldrian, P., 2013. Bacterial communities in tetrachloroethene-polluted groundwaters: a case study. Science of the Total Environment 454-455, 517-527.

Krustok, I., Truu, J., Odlare, M., Truu, M., Ligi, T., Tiirik, K., Nehrenheim, E., 2015. Effect of lake water on algal biomass and microbial community structure in municipal wastewater-based labscale photobioreactors. Applied Microbiology and Biotechnology 99, 6537-6549.

Kuo, H.C., Juang, D.F., Yang, L., Kuo, W.C., Wu, Y.M., 2014. Phytoremediation of soil contaminated by heavy oil with plants colonized by mycorrhizal fungi. International Journal of Environmental Science and Technology 11, 1661-1668.

Li, H., Liu, D.F., Lian, B., Sheng, Y., Dong, H.L., 2012. Microbial diversity and community structure on corroding concretes. Geomicrobiology Journal 29, 450-458.

Lin, Z., Bai, J., Zhen, Z., Lao, S.Q., Li, W.Y., Wu, Z.H., Li, Y.T., Spiro, B., Zhang, D.Y., 2016. Enhancing pentachlorophenol degradation by vermicomposting associated bioremediation. Ecological Engineering 87, 288-294.

Liu, X., Wang, Z., Zhang, X., Wang, J., Xu, G., Cao, Z., Zhong, C., Su, P., 2011. Degradation of diesel-originated pollutants in wetlands by Scirpus triqueter and microorganisms. Ecotoxicology and Environmental Safety 74, 1967-1972.

Ma, B., He, Y., Chen, H.H., Xu, J.M., Rengel, Z., 2010. Dissipation of polycyclic aromatic hydrocarbons (PAHs) in the rhizosphere: synthesis through meta-analysis. Environmental Pollution 158, 855-861.

Martins, L.F., Antunes, L.P., Pascon, R.C., de Oliveira, J.C., Digiampietri, L.A., Barbosa, D., Peixoto, B.M., Vallim, M.A., Viana-Niero, C., Ostroski, E.H., Telles, G.P., Dias, Z., da Cruz, J.
B., Juliano, L., Verjovski-Almeida, S., da Silva, A.M., Setubal, J.C., 2013. Metagenomic analysis of a tropical composting operation at the são paulo zoo park reveals diversity of biomass degradation functions and organisms. PLoS One 8, e61928.

Megharaj, M., Ramakrishnan, B., Venkateswarlu, K., Sethunathan, N., Naidu, R., 2011. Bioremediation approaches for organic pollutants: a critical perspective. Environment International 37, 1362-1375.

Nissilä, M.E., Tähti, H.P., Rintala, J.A., Puhakka, J.A., 2011. Effects of heat treatment on hydrogen production potential and microbial community of thermophilic compost enrichment cultures. Bioresource Technology 102, 4501-4506.

Oturan, M.A., Peiroten, J., Chartrin, P., Acher, A.J., 2000. Complete destruction of $p$-nitrophenol in aqueous medium by electro-fenton method. Environmental Science \& Technology 34, 3474-3479.

Qin, H., Brookes, P.C., Xu, J., 2016. Arbuscular mycorrhizal fungal hyphae alter soil bacterial community and enhance polychlorinated biphenyls dissipation. Frontiers in Microbiology 7, 939.

Qin, H., Brookes, P.C., Xu, J., Feng, Y., 2014. Bacterial degradation of Aroclor 1242 in the mycorrhizosphere soils of zucchini (Cucurbita pepo L.) inoculated with arbuscular mycorrhizal fungi. Environmental Science and Pollution Research International 21, 1279012799.

Qiu, X., Fang, Z., Liang, B., Gu, F., Xu, Z., 2011. Degradation of decabromodiphenyl ether by nano zero-valent iron immobilized in mesoporous silica microspheres. Journal of Hazardous Materials 193, 70-81.

Qu, W., Bi, X., Sheng, G., Lu, S., Fu, J., Yuan, J., Li, L., 2007. Exposure to polybrominated diphenyl ethers among workers at an electronic waste dismantling region in Guangdong, China. Environment International 33, 1029-1034.

Robrock, K.R., Coelhan, M., Sedlak, D.L., Alvarez-Cohent, L., 2009. Aerobic biotransformation of polybrominated diphenyl ethers (PBDEs) by bacterial isolates. Environmental Science \& Technology $43,5705-5711$.

Schmalenberger, A., O'Sullivan, O., Gahan, J., Cotter, P.D., Courtney, R., 2013. Bacterial communities established in bauxite residues with different restoration histories. Environmental Science \& Technology 47, 7110-7119.

Shabarova, T., Villiger, J., Morenkov, O., Niggemann, J., Dittmar, T., Pernthaler, J., 2014. Bacterial community structure and dissolved organic matter in repeatedly flooded subsurface karst water pools. FEMS Microbiology Ecology 89, 111-126.

Shiyin, L., Lixiao, N., Panying, P., Cheng, S., Liansheng, W., 2004. Effects of pesticides and their hydrolysates on catalase activity in soil. Bulletin of Environmental Contamination and Toxicology 72 , 600-606.

Sjödin, A., Hagmar, L., Klasson-Wehler, E., Kronholm-Diab, K., Jakobsson, E., Bergman, A., 1999. Flame retardant exposure: polybrominated diphenyl ethers in blood from Swedish workers. Environmental Health Perspectives 107, 643-648.

Stepniewska, Z., Wolińska, A., Ziomek, J., 2009. Response of soil catalase activity to chromium contamination. Journal of Environmental Sciences (China) 21, 1142-1147.

Uhlik, O., Wald, J., Strejcek, M., Musilova, L., Ridl, J., Hroudova, M., Vlcek, C., Cardenas, E., Mackova, M., Macek, T., 2012. Identification of bacteria utilizing biphenyl, benzoate, and naphtha- 
lene in long-term contaminated soil. PLoS One 7, e40653.

Vergani, L., Mapelli, F., Zanardini, E., Terzaghi, E., Di Guardo, A., Morosini, C., Raspa, G., Borin, S., 2017. Phyto-rhizoremediation of polychlorinated biphenyl contaminated soils: An outlook on plantmicrobe beneficial interactions. Science of the Total Environment 575, 1395-1406.

Walker, D.J., Clemente, R., Bernal, M.P., 2004. Contrasting effects of manure and compost on soil $\mathrm{pH}$, heavy metal availability and growth of Chenopodium album L. in a soil contaminated by pyritic mine waste. Chemosphere 57, 215-224.

Wang, S., Zhang, S., Huang, H., Christie, P., 2011a. Behavior of decabromodiphenyl ether (BDE-209) in soil: effects of rhizosphere and mycorrhizal colonization of ryegrass roots. Environmental Pollution 159, 749-753.

Wang, Y., Luo, C., Li, J., Yin, H., Li, X., Zhang, G., 2011 b. Characterization of PBDEs in soils and vegetations near an ewaste recycling site in South China. Environmental Pollution 159, 2443-2448.

Wang, Y., Luo, C., Li, J., Yin, H., Zhang, G., 2014. Influence of plants on the distribution and composition of PBDEs in soils of an e-waste dismantling area: evidence of the effect of the rhizosphere and selective bioaccumulation. Environ Pollut 186, 104-109.

Wang, Y., Yu, Z., Li, Y., Wang, G., Liu, J., Liu, J., Liu, X., Jin, J., 2017. Microbial association with the dynamics of particulate organic carbon in response to the amendment of elevated $\mathrm{CO}_{2}$-derived wheat residue into a Mollisol. Science of the Total Environment 607-608, 972-981.

Wei, H., Zou, Y., Li, A., Christensen, E.R., Rockne, K.J., 2013. Photolytic debromination pathway of polybrominated diphenyl ethers in hexane by sunlight. Environmental Pollution 174, 194 200.

Wu, F., Yu, X., Wu, S., Wong, M., 2014. Effects of inoculation of PAHdegrading bacteria and arbuscular mycorrhizal fungi on responses of ryegrass to phenanthrene and pyrene. International Journal of Phytoremediation 16, 109-122.

Xie, X., Qian, Y., Xue, Y., He, H., Wei, D., 2013. Plant uptake and phytotoxicity of decabromodiphenyl ether (BDE-209) in ryegrass (Lolium perenne L). Environmental Science. Processes \& Impacts 15, 1904-1912.

Xu, Y., He, Y., Feng, X., Liang, L., Xu, J., Brookes, P.C., Wu, J., 2014. Enhanced abiotic and biotic contributions to dechlorination of pentachlorophenol during $\mathrm{Fe}$ (III) reduction by an iron-reducing bacterium Clostridium beijerinckii Z. Science of the Total Environment 473-474, 215-223.

Xu, Y., He, Y., Tang, X., Brookes, P.C., Xu, J., 2017. Reconstruction of microbial community structures as evidences for soil redox coupled reductive dechlorination of PCP in a mangrove soil. Science of the Total Environment 596-597, 147-157.

Xu, Y., He, Y., Zhang, Q., Xu, J., Crowley, D., 2015. Coupling between pentachlorophenol dechlorination and soil redox as revealed by stable carbon isotope, microbial community structure, and biogeochemical data. Environmental Science \& Technology 49, 5425-5433.

Xue, L., Feng, X., Xu, Y., Li, X., Zhu, M., Xu, J., He, Y., 2017. The dechlorination of pentachlorophenol under a sulfate and iron reduction co-occurring anaerobic environment. Chemosphere 182, 166-173.

Zhang, C., Du, Y., Tao, X.Q., Zhang, K., Shen, D.S., Long, Y.Y., 2013. Dechlorination of polychlorinated biphenyl-contaminated soil via anaerobic composting with pig manure. Journal of Hazardous Materials 261, 826-832.

Zhang, J.Y., Liu, X.Y., Liu, S.J., 2009. Adhaeribacter terreus sp. nov., isolated from forest soil. International Journal of Systematic and Evolutionary Microbiology 59, 1595-1598.

Zhang, Y., Luo, X.J., Mo, L., Wu, J.P., Mai, B.X., Peng, Y.H., 2015. Bioaccumulation and translocation of polyhalogenated compounds in rice (Oryza sativa L.) planted in paddy soil collected from an electronic waste recycling site, South China. Chemosphere 137, 25-32.

Zhao, X.R., Qin, Z.F., Yang, Z.Z., Zhao, Q., Zhao, Y.X., Qin, X.F., Zhang, Y.C., Ruan, X.L., Zhang, Y.F., Xu, X.B., 2010. Dual body burdens of polychlorinated biphenyls and polybrominated diphenyl ethers among local residents in an e-waste recycling region in Southeast China. Chemosphere 78, 659-666.

Zhou, J., Xia, F., Liu, X.M., He, Y., Xu, J.M., Brookes, P.C., 2014. Effects of nitrogen fertilizer on the acidification of two typical acid soils in South China. Journal of Soils and Sediments 14, 415422.

Zhu, H., Wang, Y., Wang, X., Luan, T., Tam, N.F.Y., 2014. Intrinsic debromination potential of polybrominated diphenyl ethers in different sediment slurries. Environmental Science \& Technology 48, 4724-4731. 